University of Louisville

ThinkIR: The University of Louisville's Institutional Repository

Electronic Theses and Dissertations

$5-2020$

\title{
Geographic imaginaries of urban spatial segregation: a case study of the west end neighborhoods in Louisville, Kentucky.
}

Amber Dock

University of Louisville

Follow this and additional works at: https://ir.library.louisville.edu/etd

Part of the African American Studies Commons, American Politics Commons, Geographic Information Sciences Commons, Human Geography Commons, United States History Commons, and the Urban

Studies Commons

\section{Recommended Citation}

Dock, Amber, "Geographic imaginaries of urban spatial segregation: a case study of the west end neighborhoods in Louisville, Kentucky." (2020). Electronic Theses and Dissertations. Paper 3467.

https://doi.org/10.18297/etd/3467

This Master's Thesis is brought to you for free and open access by ThinkIR: The University of Louisville's Institutional Repository. It has been accepted for inclusion in Electronic Theses and Dissertations by an authorized administrator of ThinkIR: The University of Louisville's Institutional Repository. This title appears here courtesy of the author, who has retained all other copyrights. For more information, please contact thinkir@louisville.edu. 


\title{
GEOGRAPHIC IMAGINARIES OF URBAN SPATIAL SEGREGATION: A CASE STUDY OF THE WEST END NEIGHBORHOODS IN LOUISVILLE, KENTUCKY
}

\author{
By \\ Amber Dock \\ B.A. Ohio State University, 2018 \\ A Thesis \\ Submitted to the Faculty of the \\ College of Arts and Sciences of the University of Louisville \\ in Partial Fulfillment of the Requirements \\ for the Degree of \\ Master of Science \\ in Applied Geography \\ Department of Geography and Geosciences \\ University of Louisville \\ Louisville, KY
}

May 2020 

GEOGRAPHIC IMAGINARIES OF URBAN SPATIAL SEGREGATION: A CASE STUDY OF THE WEST END NEIGHBORHOODS IN LOUISVILLE, KENTUCKY

By

Amber Dock

B.A. Ohio State University, 2018

A Graduate Thesis Approved on

April 17, 2020

by the following Thesis Committee

Dr. Margath Walker, Chair

Matthew H. Ruther

Carrie Mott 


\section{ACKNOWLEDGMENTS}

I would like to thank the Department of Geography and Geosciences at the University of Louisville for the financial support allowing me the opportunity to conduct such interesting and applicable research with the guidance of brilliant faculty members. I would like to thank Dr. Margath Walker for being my primary advisor and being a truly invaluable resource along the way; Dr. Carrie Mott and Dr. Matt Ruther for being my secondary and outside advisor, respectively; my fellow graduate students for their continued encouragement and friendship; and my family for encouraging me to pursue this dream of mine. 


\begin{abstract}
GEOGRAPHIC IMAGINARIES OF URBAN SPATIAL SEGREGATION: A CASE STUDY OF THE WEST END NEIGHBORHOODS IN LOUISVILLE, KENTUCKY

Amber Dock
\end{abstract}

April 17, 2020

The objective of this thesis is to translate the framework of geographic imaginaries into an urban context in order to capture a narrative of how residents conceptualize and experience segregation. This framework is rooted in an investigation of local discourses as they exist within a specific social, political, and historical context. Institutionalized segregation and structural racism are the foundations on which the American urban context studied here was built upon. This study employs multiple methods, including contextualizing the study area, analyzing discursive content, and visualizing the results. The results of these analyses included empirically connecting concentrations of protected classes to limited access to vital local resources and identifying three discursive themes: territorial stigmatization, specific calls for change, and sense of community. These results were synthesized and visualized in order to develop a narrative of geographic imaginaries from multiple positionalities. 


\section{TABLE OF CONTENTS}

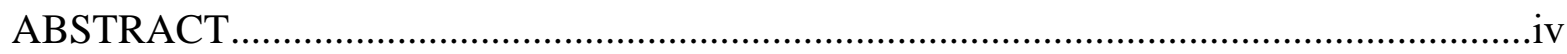

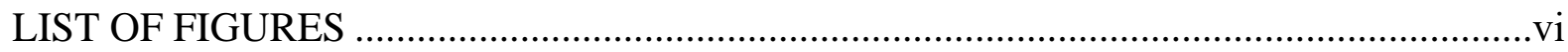

LIST OF TABLES .......................................................................................................

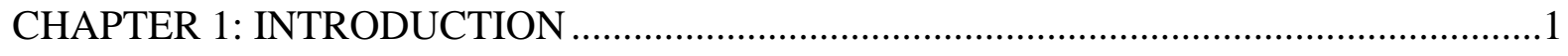

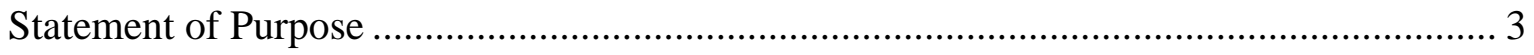

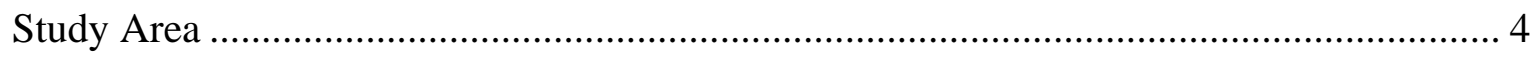

Historical and Contemporary Significance..................................................................... 10

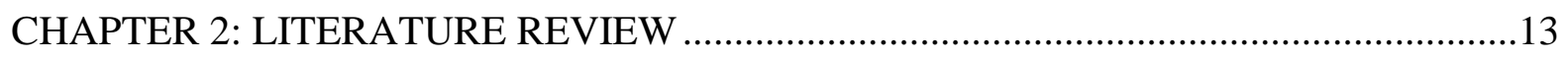

Contextualization of Framework ................................................................................... 14

Urban Spatial Segregation .................................................................................. 19

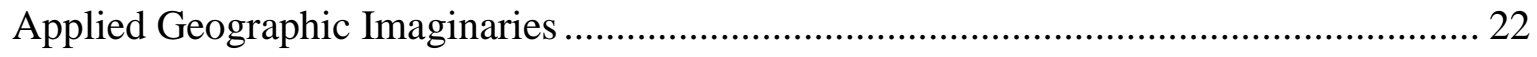

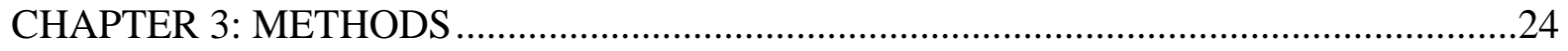

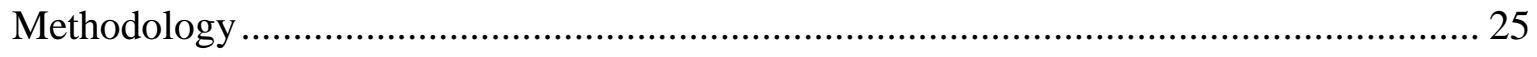

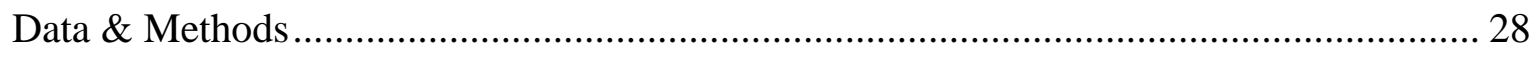

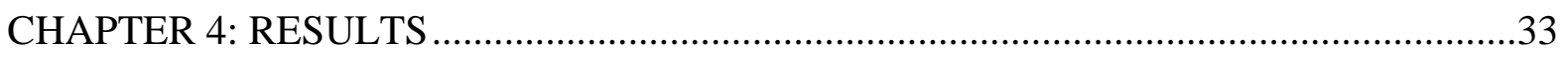

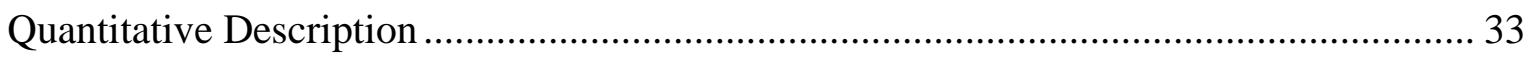

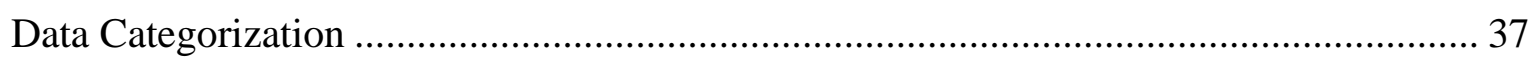

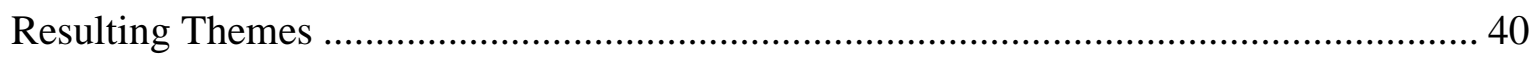

Theme 1: Territorial Stigmatization........................................................................... 41

Theme 2: Specific Calls for Change ……………………........................................... 44

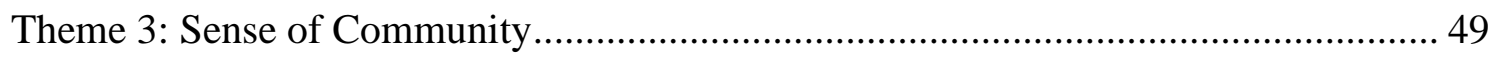


Qualitative Visualization

CHAPTER 5: DISCUSSION OF RESULTS ...............................................................61

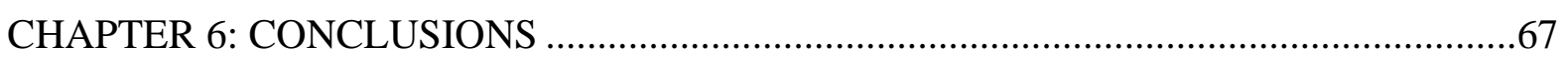

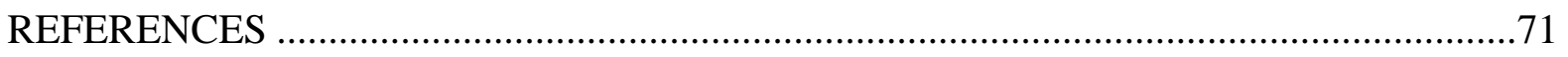

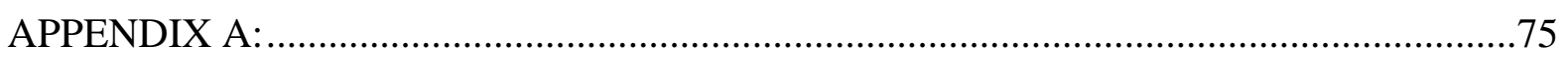

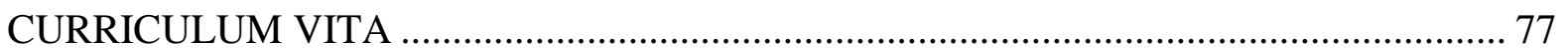




\section{LIST OF FIGURES}

Figure 1.1: Map of West End Neighborhoods and the location of Jefferson County within the state of Kentucky …………….............................................................. 5

Figure 1.2: Redlining Map of Louisville, Kentucky .................................................. 7

Figure 1.3: A significant demographic shift occurred while urban renewal projects

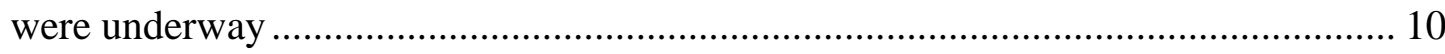

Figure 4.1: ArcGIS Online Map of accessibility to Louisville amenities, specifically libraries and parks, in relation to vehicle ownership rates.

Figure 4.2: Georeferenced redlining map overlaid with modern neighborhood

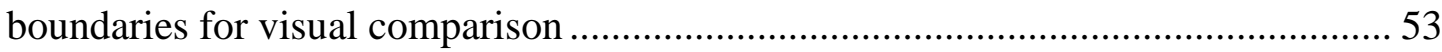

Figure 4.3: ArcGIS Online Map of accessibility to Louisville grocery stores in relation to vehicle ownership rates

Figure 4.4: Screen capture of the online Esri StoryMap documenting some of the components of the geographic imaginations for the discourse originating from West

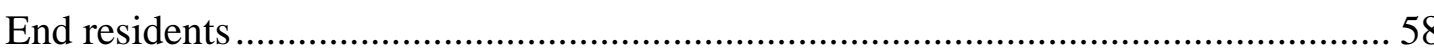

Figure 4.5: Screen capture of the online Esri StoryMap documenting some of the components of the geographic imaginations for the dominant discourse of Louisville residents

Figure A.1: Word Cloud generated with quotations from University of Louisville's Oral History Center Archive. 76

Figure A.2: Word Cloud generated with quotations from the West of Ninth Stories 76 


\section{LIST OF TABLES}

Table 4.1: West End Neighborhood Profiles. Data from Kentucky Data Center. ..... 34

Table 4.2: Tabulated results of environmental analyses on accessibility to parks and

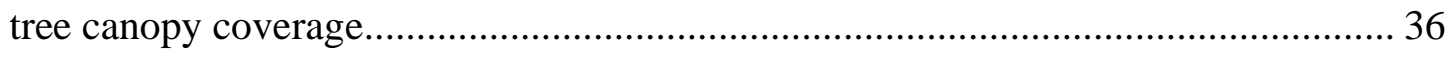

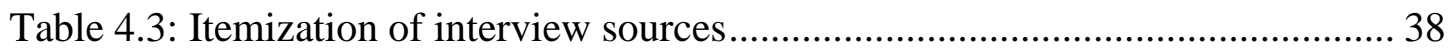

Table 4.4: Classification scheme used for content and discourse analysis ................. 39 


\section{CHAPTER 1: INTRODUCTION}

A geographic imaginary is a concept used throughout the social sciences to describe the way in which an area is perceived to be based on the popular discourse within a community. Within the framework of geographic imaginaries, discourse is engaged as a way to analyze these contemporary perceptions and to contextualize them within the different structural power dynamics shaping them. Power, as it is conceptualized here, is located in the process of producing discourse (Wacquant, Slater, and Pereira 2014). While it can be empowering to dictate your own discourse, discourses are most commonly defined from a position above or outside of the context it describes. The development of a dominating discourse from this vantage point can serve as a way of accentuating differences between communities and building a sense of isolation or exclusion based on these differences.

The density and diversity of populations within urban areas makes these spaces ideal for investigating the influence that local discourses have in sustaining the conceptualization of these communities as different. The development of these discourses needs to be contextualized within the history of institutionalized segregation and structural racism that is so foundational to the American urban landscape. The stark patterns of spatialized segregation along lines of race and class cannot be fully grasped without grounding practices such as redlining, urban renewal, and gentrification within this history. These practices, in effect, privileged white homebuyers by granting them mortgage loans at low interest rates 
and robbed people of color the opportunity to gain equity on homes or to live wherever they pleased for generations. Redlining began as a thinly veiled housing segregation strategy which classified residential areas based on the perceived level of risk for investment which resulted in areas with concentrations of non-white residents to be classified as 'high-risk' investment zones. While illegal now, the impact of redlining can still be seen on the landscape today and will be a topic of further discussion in this analysis (Gieseking 2017; Shelton 2017). Gentrification, and urban renewal schemes more broadly, is the redevelopment of impoverished urban areas made possible through the forced removal of residents. The sites selected for this type of redevelopment are typically characterized as mixed commercial and low income residential on high value land which is then converted to expensive housing, high end commercial districts, and significantly fewer housing options for dislocated residents hoping to return (Rothstein 2017; Metropolitan Housing Coalition; Hinko 2012).

This framework of geographic imaginaries is applied to the historically redlined neighborhoods of Louisville's West End District in order to document how residents conceptualize and internalize segregation within an urban context. The framework of geographic imaginaries has the potential to empower historically disenfranchised communities within Louisville by engaging locals in the knowledge production process. Granting individuals the opportunity to dictate their own discourse is a means of distributing the power of representation amongst the researcher and the researched and their perspectives can then be situated within the broader socio-political context (Kwan 2002, 2012a; Baxter and Eyles 1999; Walker and Hanchette 2015). 


\section{STATEMENT OF PURPOSE}

The objective of this thesis is to translate geographic imaginaries into an urban context in order to document how residents of historically redlined neighborhoods think about segregation. This study will be grounded in an analysis of the West End neighborhoods of Louisville, Kentucky where the degree of socioeconomic disparity has been widely documented; in fact, some news sources ranked it as high as the fourth most racially segregated city in the country (Kent and Frohlich 2015). Segregation manifests throughout numerous aspects of everyday life. In Louisville this includes the division of consumer markets along neighborhood lines which have led to food deserts and a lack of jobs; concentrations of poverty; unequal distribution of green spaces; and unequal access to vital services such as adequate healthcare. An aspect of geographic imaginaries within this urban context that will be explored further is the way in which residents internalize the physical and mental boundaries resulting from these discriminatory policies (Madsen and Ruderman 2016).

This framework applied to studies on urban spatial segregation allows new types of questions to be addressed, including how residents conceptualize boundaries, both physical and emotional, and how the internalization of geographic imaginations influence the visual perception of their Louisville. This translation of geographic imaginaries to an urban context will be accomplished using a three-pronged approach: 1) Contextualization of the study area utilizing multiple quantitative data sources; 2) Content and discourse analyses of archival and interview materials; and 3) Mixed-methodological incorporation of qualitative GIS in order to put the past in conversation with the present. By merging qualitative and quantitative 
analytical methods, the final product will be a new means of visualizing residents' geographic imaginaries of spatial segregation as a series of maps.

This thesis is structured in the following way. This first chapter will continue by historically contextualizing the West End within the socio-political history of Louisville's development and close by emphasizing the significance of this application to Louisville specifically. Chapter 2 is a literature review of geographic imaginaries as a conceptual framework and of urban spatial segregation. The final section of this chapter connects these two literatures and outlines how this framework will be applied to this urban context. Chapter 3 is concerned with the methodologies employed in this study as well as the methods used to carry it out. The primary methodological tools include content and discourse analysis, spatial analysis through GIS, and grounded visualization of the results. Chapter 4 documents the results of the multiple analyses and synthesizes them down to three resulting themes which will be discussed in more detail in Chapter 5 with respect to each of the different sources of data. The final chapter, Chapter 6, assesses the application of geographic imaginaries into an urban context, outlines the implications of the results, and discusses how this framework could be improved upon in future research.

\section{STUDY AREA}

Louisville Kentucky is situated along the Ohio River in northwestern Kentucky and is the largest city in the state with a population of 767,000 within its county (US Census Bureau, 2019). In 2003 the Louisville city government merged with that of the county, Jefferson County, and thus provides a clear designation of Louisville's boundaries which will be used throughout this research (Metropolitan Housing Coalition, 2010). The study area for 
this analysis consists of the nine neighborhoods in Louisville's West End District, an area located west of Downtown, and is shown below in Figure 1.1. This area is characterized by lower household incomes, majority-minority demographics, older housing stock, and limited access to vital resources such as adequate healthcare and healthy food (Metropolitan Housing Coalition, 2010; Anne Braden Institute, 2013; Reid 2013). These factors are all directly related to the high degree of racial segregation exhibited in the area with African Americans constituting upwards of $80 \%$ of the West End population and only $20 \%$ of Jefferson County

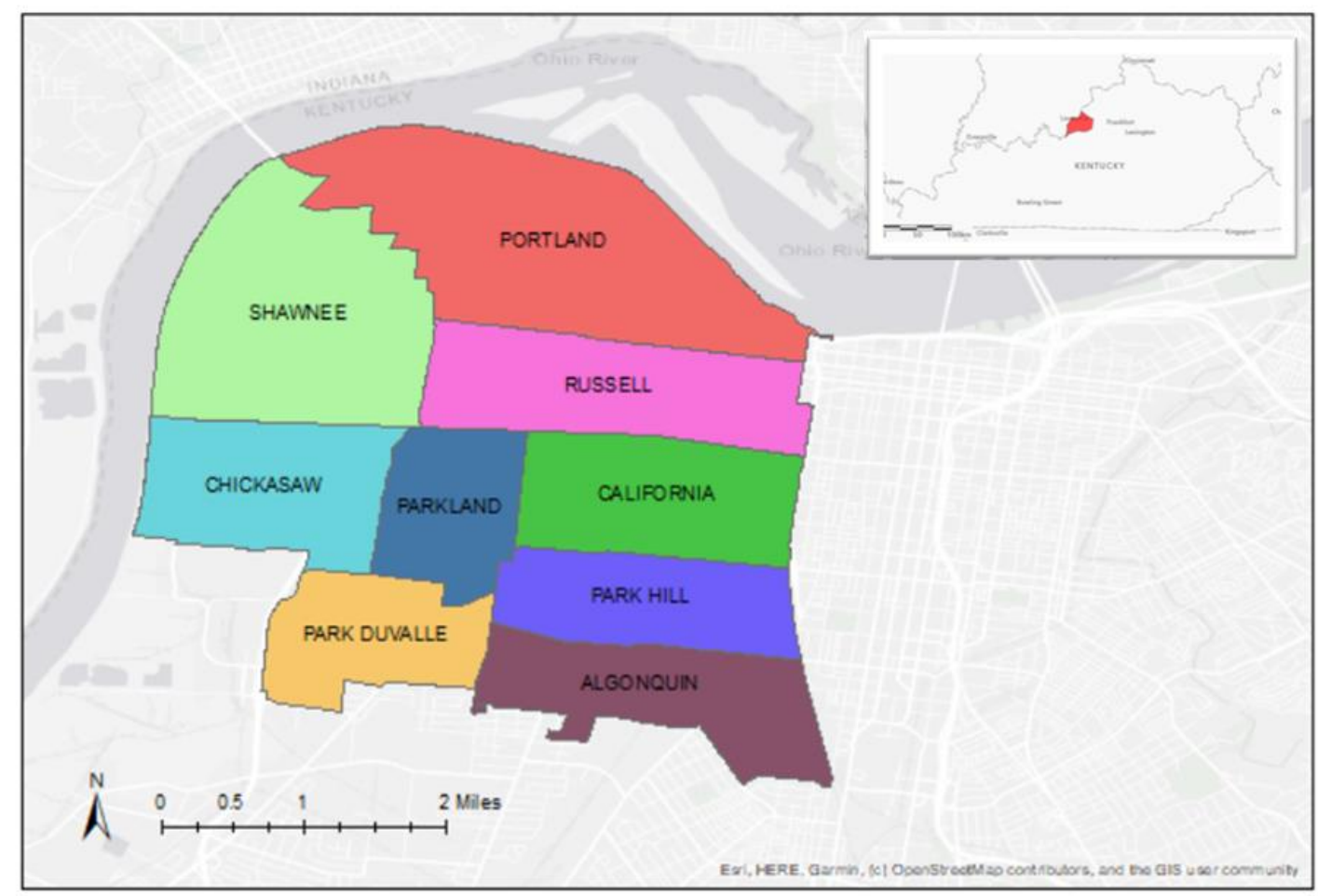

Figure 1.1: Map of West End Neighborhoods and the location of Jefferson County within the state of Kentucky as a whole (Anne Braden Institute, 2013).

The history of racial segregation in the West End dates back to Louisville's first days as a trading city and in order to historically contextualize this spatial segregation, this study will begin by outlining how the city developed and the dramatic demographic switch in the 
mid twentieth century. Louisville was founded as a port city at the Falls of the Ohio where river boats would have to dock and transfer their cargo to a vessel downstream of the Falls (Anne Braden Institute, 2013). Much of Louisville's early development resulted from this river economy and was reflected in the patterns of settlement and commercial growth being concentrated along the northern shore where the Downtown area is still located today (Anne Braden Institute, 2013). Racialized segregation was a recognized feature of society through the nineteenth century and adopted officially in 1914 by the Louisville Board of Alderman. This ordinance enforced segregated housing where streets and blocks were not allowed to integrate due to fears of property devaluation (Anne Braden Institute, 2013; Rothstein 2017). The verdict of the Supreme Court case Buchanan v. Warley ruled this type of residential segregation unconstitutional in 1917 (Anne Braden Institute, 2013; Rothstein 2017). The ruling was ineffective at preventing the institutionalization of housing segregation that steadfastly continued throughout the twentieth century through a whole array of actors such as lending institutions, real estate agencies, and residential development firms.

An example of this ruling being circumvented was the creation of the Home Owner's Loan Corporation (HOLC) in 1933 which granted home loans disproportionately to white people seeking to live in white neighborhoods (Anne Braden Institute, 2013; Rothstein 2017). This was accomplished by categorizing neighborhood areas based on the perceived risk of investment with grades ranging from A, represented as Green zones, to D, represented as Red zones, hence the term redlining (Rothstein 2017). The grade of an area was greatly dependent on the demographic composition where areas populated by black people were classified as high-risk investment zones (Rothstein 2017; Anne Braden Institute, 2013). This meant mortgage loan rates for black residents were very high, or not offered at all, which 
effectively made homeownership impossible for an entire demographic (Metropolitan Housing Coalition, 2010; Rothstein 2017). In 1936 a map was commissioned by the HOLC to grade the residential areas of Louisville. The results of this can be seen below in Figure

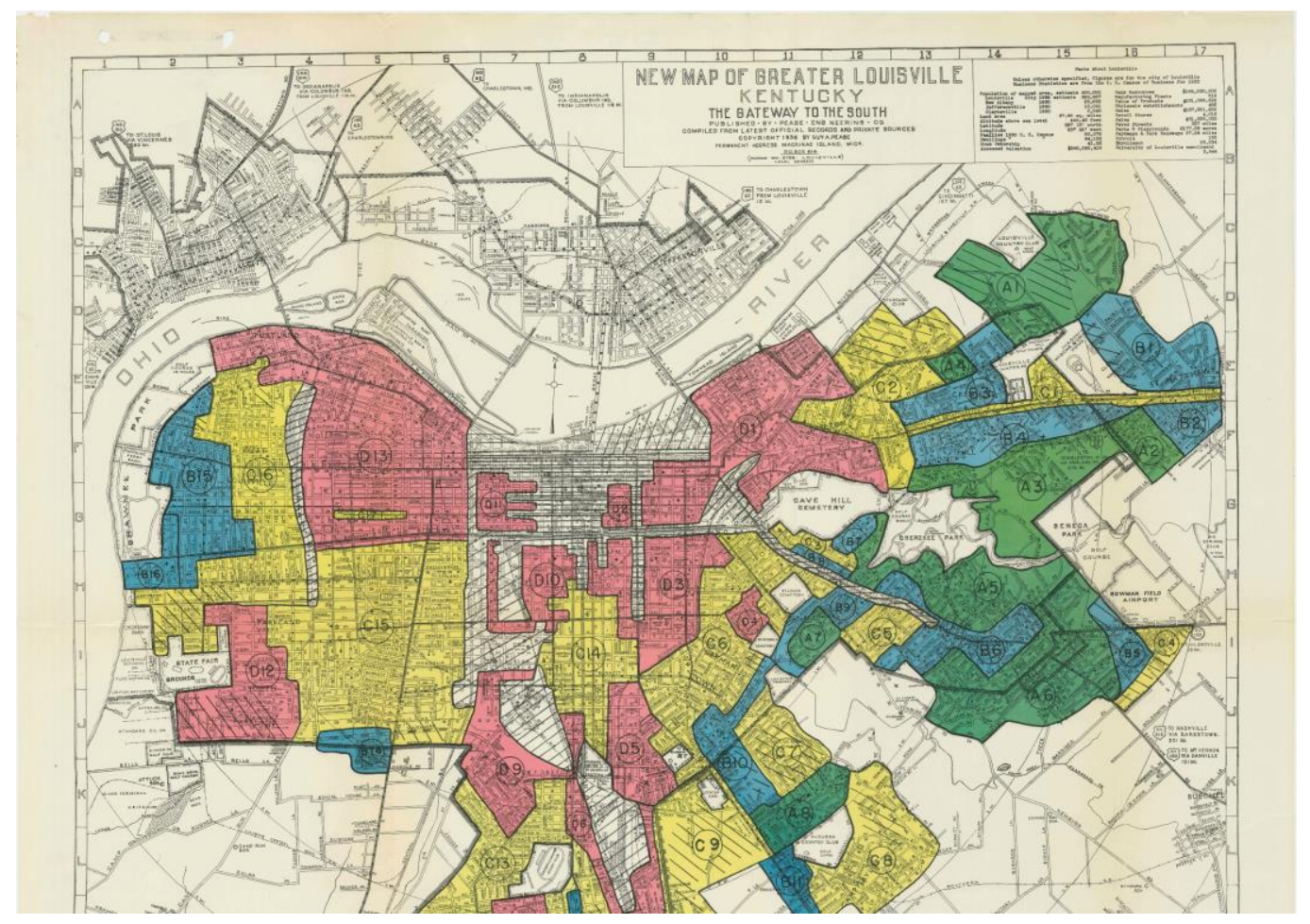

Figure 1.2: Redlining Map of Louisville, Kentucky Image from the University of Louisville' Libraries Digital Collections

1.2 , and notice how the West End is primarily classed as C and D.

In 1937 there was a significant flood which displaced hundreds of thousands of Louisville residents and inundated much of the western side of the city. Figure 1.3 below illustrates the extent of the city impacted by flood waters and records the water depth reaching up to 12.4 feet along W Broadway St. The flood of 1937 is connected to the segregated neighborhoods of today in that the massive white exodus that began at this time opened up these areas to black residents for the first time (Anne Braden Institute, 2013). The 
flood was the first in a series of events resulting in the demographic reorganization of urban Louisville followed by GI Bill sponsored white suburbanization and then by urban renewal in the 1950s through 1970s (Anne Braden Institute, 2013; Hammond 1979). In addition to the demographic impact of the flood, this event was also instrumental in establishing the housing characteristics which define the western side of the city today: single family dwellings built before 1940 (Anne Braden Institute, 2013). First, single family homes are less affordable than other types of housing such as multi-family units or public housing options, and second, the housing stock in the West End is some of the oldest in the city with only the historic district Old Louisville south of Downtown sustaining a higher concentration of old homes (Metropolitan Housing Coalition, 2010; Anne Braden Institute, 2013). The issues with old housing include high maintenance costs, poor insulation leading to high heating and cooling costs, and the potential health and safety hazards due to exposure to lead and asbestos (Metropolitan Housing Coalition, 2010; Anne Braden Institute, 2013).

Housing shortages were a chronic issue for Louisville, among many other cities, because the housing stock available to them was limited and, as described above, ill-fitting for the people seeking a home (Anne Braden Institute, 2013; Rothstein 2017; Hinko 2012). In Louisville, public housing projects were developed in order to improve urban living conditions, specifically segregated urban living, by building projects in pairs so that one would accommodate white and the others blacks (Anne Braden Institute, 2013; Metropolitan Housing Coalition, 2010). This was the case with the 1937 pair of College Court, black, and LaSalle Place, white, and again in 1940 with Beecher Terrace, black, and Clarksdale, white (Anne Braden Institute, 2013). The housing needs of black residents were, however, still not being met because whites had more housing options through programs such as the GI Bill 
and therefore the white urban housing projects had vacancies while their black counterparts had long wait lists and experienced overcrowding (Rothstein 2017). The GI Bill was passed after World War 2 and offered whites the opportunity to purchase homes in new suburbs at low interest rates which sustained the pattern of white migration out of the city beginning years before (Rothstein 2017; Alexander 1977; Jones 1977).

Louisville undertook extensive urban renewal projects beginning in the 1950s which negatively impacted black residents at much higher rate than white residents (Anne Braden Institute, 2013; Hobich 1977). Hit particularly hard was the thriving African American business district along Walnut Street, now Muhammad Ali Blvd, which was destroyed in order to build I-65 (Anne Braden Institute, 2013). Businesses which were displaced at this time often could not afford to reopen because their commercial space was rented and therefore they did not receive any financial compensation with their notice to leave (Hobich 1977). The degree to which urban renewal projects displaced and disadvantaged black populations is reflected in the notion of "urban renewal is black removal" which was commonly expressed across America's segregated cityscapes and Louisville was no exception (Rothstein 2017; Anne Braden Institute, 2013). West Louisville was further isolated economically as a result of the racially-motivated riots of 1968 in the once thriving and self-sufficient Parkland neighborhood which led to a rise in break in rates, businesses closing, and investment, both public and private, going elsewhere (Anne Braden Institute, 2013; Ebbs 1977; Alexander 1977; Goodwin 1979). The demographic shift that took place during this period of white flight, suburbanization, and dislocation from urban renewal projects is illustrated and summarized below in Figure 1.3. 

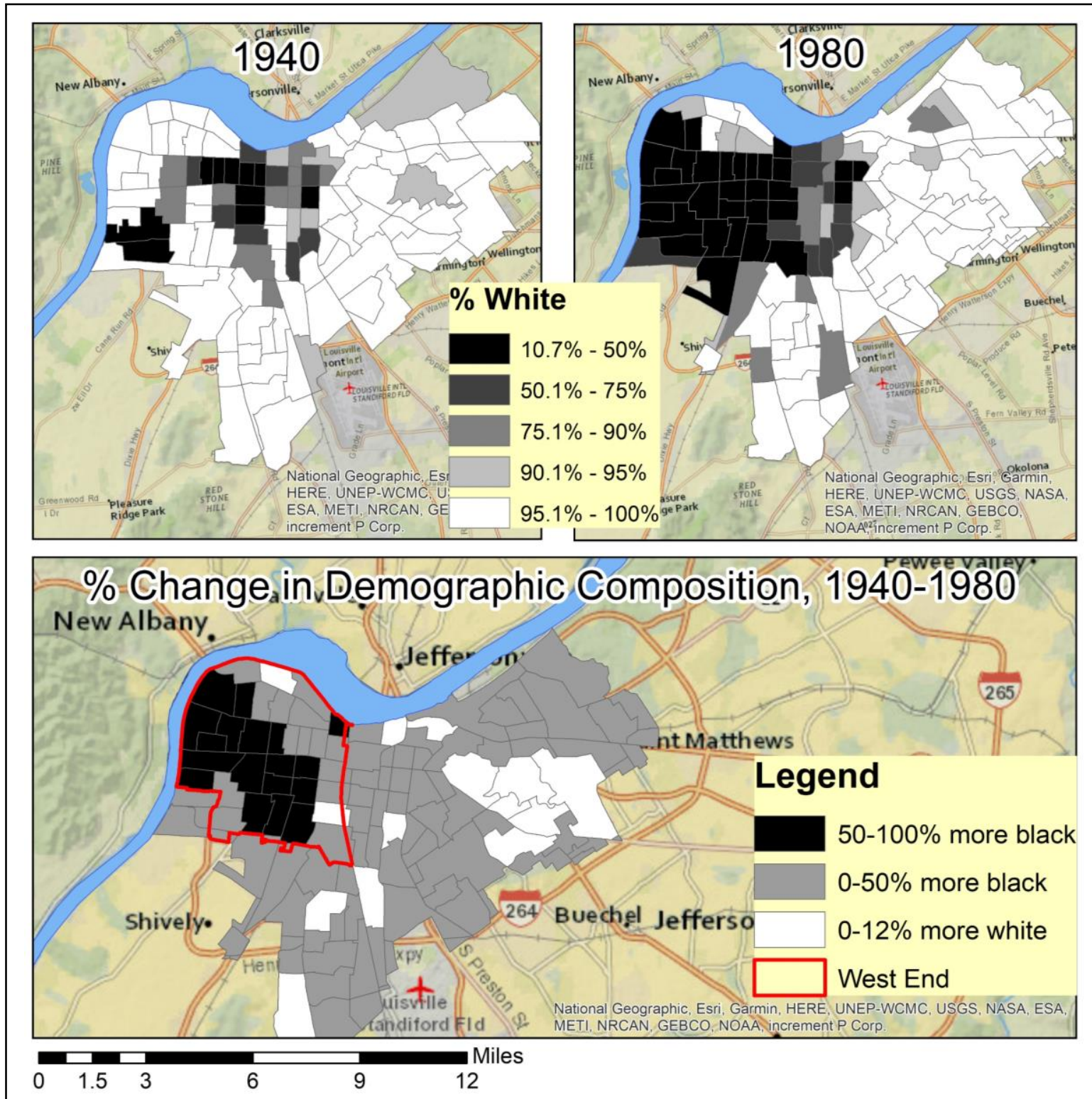

Figure 1.3: A significant demographic shift occurred while urban renewal projects were underway

\section{HISTORICAL AND CONTEMPORARY SIGNIFICANCE}

The previous section illustrated the deeply influential role of Louisville's history of structural racism on current residential patterns and justified the claim that these must be considered together in order to develop meaningful solutions. Economist Richard Rothstein identifies two different forms of segregation: de jure and de facto. De jure segregation 
constitutes discriminatory policies such as redlining and certain residential ordinances. De facto segregation is the internalization of a world view where segregation is natural, inevitable, or correct. Through this lens, the concentration of impoverished non-white people is accepted as being reflective of free choice, as responsible for their economic situation, and as a justifiable target for demolition in pursuit of urban re/development projects. In effect, de jure segregation led to this pattern of residential segregation and the sentiments associated with de facto segregation keep this pattern in place. The degree of the racial segregation exhibited in Louisville has been well documented, recognized nationally as one of the top ten most racially segregated cities, with $45 \%$ of the population living in "extreme" racial segregation (Kent and Frohlich 2015; Metropolitan Housing Coalition, 2010; Anne Braden Institute, 2013). In 2013 Louisville Magazine published a story which said:

"Any Louisvillian who has lived here for more than a few years knows, almost instinctively, the boundary line between west Louisville and the rest of Louisville: Ninth Street. Most white Louisvillians know it because they've heard some variation of the warning, 'Don't go west of Ninth Street.'...Although the notion that west Louisville is a dangerous and even foreign place is embedded in the mental map that many of us...carry around in our heads, it is rarely talked about in public" (Crutcher 2013).

The internalization of such a mental map perpetuates the discourse of the "west and the rest" which together act to frame the city as divided along a hard boundary. This divisive discourse originated from entities outside of the west and has come to dominate the discourse surrounding activities in west (Shelton, Poorthuis, and Zook 2015). This study, with the objective of applying geographic imaginaries to an urban context, was designed to dismantle this conceptualization of a single dominating discourse by involving residents in the process of representation. As local geographic imaginaries are put into conversation with the 
dominating discourse as well as the geographic imaginaries of those outside the west, this study will highlight the differences between them and identify necessary changes to how the West End is approached. 


\section{CHAPTER 2: LITERATURE REVIEW}

This study is informed by research conducted in the fields of urban studies, feminist geography, black geographies, economics, and sociology, yet across these fields there is not a consistent use of geography imaginaries (Wacquant, Slater, and Pereira 2014; Springer forthcoming; Silvey and Rankin 2010; Rothstein 2017; Crump 2016; Hawthorne 2019; Allen, Lawhon, and Pierce 2018). Geographic imaginaries as a term can be found across studies of the urban, however, it is engaged in a very narrow manner (Kobayashi 2004; Larson 2017; Silvey and Rankin 2010). As a term, geographic imaginaries are used to describe how changes on the landscape impact someone's spatial perception (Larson 2017). It does not grapple with the underlying causes for these changes, relate to the structural confines these changes occur within, or connect the change to the broader socio-spatial context; that is what a critical perspective can add to an analysis. Critical studies in fields such as feminist geography, black geographies, and anticolonialism strive to empower historically disenfranchised groups and communities by incorporating them into the research process through practices such as acknowledging multiple experiences, spatial imaginations, and discourses as valid and existing simultaneously; recognizing knowledge as situated within a specific socio-spatial context; and historicizing the overarching power structures (Said 1979; Gregory 1995; Allen, Lawhon, and Pierce 2018; Hawthorne 2019; Peake 2015; Rose 1997; Crump 2016).

The objective of this chapter is to illustrate how the framework of geographic imaginaries is well positioned to engage with this critical approach to research as it addresses 
perceptions of spatial segregation within the Louisville area. The first section contextualizes the framework of geographic imaginaries, going back to its first usage and the impact that this colonial history has on how it can be used in an urban environment. The second literature is urban spatial segregation which will outline the different approaches, methods, and issues associated with them. The final section details the application of the geographic imaginary framework to an urban analysis and how this is distinct from the previously discussed ways of analyzing urban spatial segregation.

\section{CONTEXTUALIZATION OF FRAMEWORK}

The geographic imagination was first engaged by Edward Said in the late 1970s as a way of "rethinking geography" where spatial representation could not be untangled from exercises of power (Said 1979; Gregory 1995). Geographic imaginations were used throughout Said's articulation of Orientalism in order to represent how a sense of otherness was established (Said 1979, 1994). Orientalism, and the conceptualization of the Orient, is hundreds of years old and refers to a way of framing the world in terms of opposites, as composed of imperial power and their imperial holdings (Said 1979; Gregory 1995, 2004). This dichotomy of the Occident versus the Orient was sustained through the Occident's role as sole source of knowledge about these faraway nations (Gregory 1995; Kobayashi 2004; Gieseking 2017). The Oriental identity was in turn constructed based on the Occident's ability to shape the narrative and to represent the Orient as devoid of power and agency, as exotic beyond understanding, and as encompassing all that which is foreign and unknowable (Mitchell 1989; Gregory 1995; Kobayashi 2004; Silvey and Rankin 2010). 
This representation of the Orient was developed from above in order to capture a culture, not the intricacies of a people, which would be consumed by populations residing outside of the Orient (Springer forthcoming; Wacquant 2006). Geographic imaginations were engaged as a discursive device to construct this narrow representation (Said 1979, 1994). There is, however, an underlying framework of geographic imaginations that can be separated from its use as a discursive device within the Orientalist ontology. This geographic imagination framework is defined by three key elements: contextualization, composition, and implications (Gregory 1995). The following discussion will identify points of connection and divergence between the framework of geographical imaginations and Orientalism with regards to these elements.

The first element of contextualization refers to the grounding of discourse within a specific place (Gregory 1995). The power of representation is practiced from outside of the place with the discourse being developed within an additional context of its own (Gieseking 2017; Springer forthcoming). In Orientalism, the context of the two places was described above as being imperial powers and imperial holdings. The contextualization therefore serves to preserve the standing of the imperial power as the seat of knowledge and all that is familiar whereas the imperial holdings are further solidified in the geographic imaginary as inferior and different (Said 1979, 1994; Mitchell 1989; Gregory 1995, 2004). The framework of geographic imaginaries remains focused on the power dynamics between the producer and subject of discourse, yet with less of an imperial lens, where the producer maintains the upper hand. When this framework is engaged with a feminist methodology, as it is in this study, contextualization involves positioning the research within the structures influencing it and reflexively positioning the researcher. Reflexive positionality refers to 
contextualizing the researcher as a non-neutral component of the research who is influenced by their connections with the research topic and subjects of research as well as by their own background. Orientalism does not engage with this concept of positionality because the position of the Occident, as the seat of power, and the Orient, as devoid of representative power, remain the same with only the specifics of the context, such as customs, varying. The second element, composition, examines the content and development of the geographic imaginary. In Orientalism, the researcher maintains their standing as outside of the scope of analysis by distancing themselves from the subjects of study and producing knowledge based on visual observation. The geographic imaginary developed through an Orientalist lens lacks critical engagement with the subjects of study because sole power to produce knowledge is reserved for the Occidental observer. The framework of geographic imaginaries, however, disperses the power to produce knowledge amongst the subjects of study, incorporates multiple discourses into this knowledge production process, and combines the perspectives of the insiders in addition to what an outsider, the researcher, can perceive. Knowledges obtained from an insider's position can be used to inform a more contextually situated geographic imaginary. This idea of knowledge as situated adds to the depth of knowledge being produced so that it includes not just discourse but also a contextualization of that discourse with the social, political, and historical structures shaping them (Moss 1995; Rose 1997).

The final element, implications, discusses the significance of the divergencies from Orientalism and how the framework of geographic imaginations can be applied to other fields of study. The framework of geographic imaginaries engages situated knowledges in order to develop a narrative that is more reflective of the specific context. Orientalism 
develops its narrative from a distance outside and above everyday life with no such goal of engaging the local. The distance established between the researcher and the subject of study differs between the frameworks of geographic imaginaries and Orientalism and this difference influences the decision in the scale of analysis. The Orientalist ontology employs distance as a way of sustaining a discourse of difference between two places and of capturing spaces on the national, regional, and hemispherical scale in order to perpetuate the stereotyped and essentializing narrative. The framework of geographic imaginaries is structured around reducing this distance by recognizing knowledge as situated, redistributing the power of representation, and capturing much smaller spaces on the scale of the city, neighborhood, and group. This redistribution of power also serves as a way of empowering the subjects of study as they contribute to the knowledge produced with their multiple and diverse points of view.

In its study of inequalities, the framework of geographic imaginaries shares many similarities to the black geographies body of literature. This discussion so far has been abstracted to categories of insider and outsider, colonizer and colonized, where race is one of many aspects of identity contextualized by geographic imaginaries. The literature of black geographies calls for a more intentional examination of race informed by the experiences of black people. This is opposed to the black experience being generalized from a discourse of the "social ills" afflicting the people across a racialized landscape (Allen, Lawhon, and Pierce 2018; Hawthorne 2019). This is directly related to geographic imaginaries' objective to empower the subjects of study by involving them in the knowledge production process. The emphasis that black geographies places on grounded research and on historical, structural contextualization has informed the development of this framework of geographic 
imaginaries. This study, however, diverges from the literature of black geographies in a few key ways. First, the spaces of exclusion investigated here, the West End neighborhoods, are conceptualized as a unit of analysis to frame the experiences of local residents as an overarching discourse and to compare against the general discourse of those outside these spaces. Black geographies would, among many things, delve deeper into the socio-political characteristics that influenced the making of these places, the definition these spaces as a unit of analysis, and the contextualization of racialized power dynamics (Allen, Lawhon, and Pierce 2018; Hawthorne 2019; McKittrick 2006). ${ }^{1}$

The framework of geographic imaginaries put forth here is structured around three key elements: contextualizing the subject of research, the research itself, and the researcher; composing a multidimensional geographic imaginary by engaging situated knowledges; and resulting in an empowering research model. Whereas power dynamics were a driving force for the Orientalist agenda, pushing a dichotomized conceptualization of power, this framework engages power dynamics in order to generate a more contextualized representation by recognizing and utilizing multiple situated knowledges. Geographic imaginaries have been described here as transforming from an Orientalist discursive device to a framework suitable for socio-spatial analysis, however, the discussion on its practical applications has remained theoretical. Urban spatial segregation has been identified as a suitable field of study to apply this framework given the dynamic power structures within the urban context. The following section will examine the tenets, approaches, and the relevant research paths of this field of study.

\footnotetext{
${ }^{1}$ See further: (Schein 1997; Shein 2003; Lipsitz 2011; McKittrick 2006; McKittrick and Woods 2007; Sundstrom 2003)
} 


\section{URBAN SPATIAL SEGREGATION}

Urban spatial segregation can be defined as a multi-faceted spatial phenomenon describing the separation between two or more entities within a region (Massey and Denton 1988; Rothstein 2017; Sadahiro 2019; Yao et al. 2018). Across the literature there is general agreement on the necessity of evaluating multiple perspectives and data sources in order to understand the complexity of the processes which resulted in the differential distribution of groups and to reflect the highly specific context (Yao et al. 2018; Massey and Denton 1988; Shelton, Poorthuis, and Zook 2015; Sadahiro 2019). There is a wide range of topics that can analyzed through an examination of urban spatial segregation, such as residential segregation, environmental inequities, and studies of intra-urban mobility (Rothstein 2017; Shelton, Poorthuis, and Zook 2015; Rey et al. 2010). These topics can be analyzed from a similarly wide range of epistemological approaches, for example, residential segregation studied from the perspective of an economist or an activist, in order to engage with the different manifestations and practices of segregation (Rey et al. 2010; Yao et al. 2018; Sadahiro 2019).

A key paper in this literature is Massey \& Denton's 1988 The Dimensions of Residential Segregation which outlines five dimensions that segregation should be measured in terms of: unevenness, exposure, concentration, centralization, and clustering. Unevenness

refers to the distribution of two groups across the region; exposure considers the likelihood of "intra-neighborhood interaction" between two groups; concentration evaluates the total area that one group occupies within the region; centralization focuses on proximity to the region's central business district; and clustering examines the composition of neighborhoods assessing whether or not there exists a pattern of homogenous neighborhoods grouping 
together (Massey and Denton 1988; Dawkins 2006). These dimensions have since been reconceptualized and distilled into two "super-dimensions" by Yao \& Wong: separateness, summarizing un/evenness, isolation, and clustering; and location, summarizing concentration and centralization (Yao et al. 2018). From the quantitative perspective, these dimensions are important because they provide a framework for a model or an index capturing that specific aspect of spatial segregation (Massey and Denton 1988; Dawkins 2006; Yao et al. 2018). Commonly used measures of spatial segregation include Spatial Proximity (SP), a measure of intragroup proximities; Spatial Exposure/Isolation Index (P); Spatial Information Theory Index (H); Spatial Relative Diversity Index (R); Spatial Dissimilarity Index (D); Neighborhood Sorting Index (NSI) for income segregation; and the Location Quotient (LQ) for spatial clustering (Reardon and O'Sullivan 2004; Yao et al. 2018). These types of measures, however, are critiqued for over-simplifying the local context through data aggregation to an areal unit which may or may not align with the true geographic context (Yao et al. 2018; Sadahiro 2019; Rey et al. 2010; Kwan 2012b, 2012a). This problem is referred to as the Uncertain Geographic Context Problem (UGCoP) and it highlights the issues of inaccurate contextualization and static, unidimensional boundaries (Kwan 2012a, 2012b; Rey et al. 2010; Yao et al. 2018). Rey et al. (2010) and Wilson (1991) support this argument by pointing to how census tracts are commonly used to approximate neighborhood boundaries and how this practice can be problematic when it is not reflective of the social context. Rey et al. (2010) go on to suggest a solution to this could start with the designation of a study area being informed both by the availability of geographic data and the socioeconomic composition of the area. 
An alternative definition of urban spatial segregation, one that builds upon the previous one, is the occupation and experience of different social environments by different groups (Reardon and O'Sullivan 2004). The addition of an experiential component is valuable because it expands the possibilities of analysis to include topics such as movement throughout the day and the intensity of intergroup influences (Reardon and O'Sullivan 2004; Rey et al. 2010; Yao et al. 2018). This reframing of urban spatial segregation as experiential also serves as a segue into a discussion with a more qualitative lens.

The spaces of the urban poor have been described as being "concentrations of poverty," as exhibiting a "culture of poverty," and as potentially remedied through a “deconcentration of poverty" (Crump 2016; Gould 1999). This discourse reduces the multidimensional experience of marginality to that of economic inequality and reframes urban segregation as a spatial issue. These simplifications rob the discussion of the poignant history of institutionalized racism (Crump 2016; Gould 1999; Wacquant 2008). Shaping the discourse in such a manner illustrates the power of representation which is directly reflected in the deeply engrained, negative discourses surrounding the "spoiled identity" of racialized urban landscapes (Wacquant, Slater, and Pereira 2014). This practice was termed "territorial stigmatization" by Wacquant (2014), defined by the dominating discourse of "vice and violence" becoming irremovable from the conceptualization of the place itself. The effects of territorial stigmatization can be brought to light through historical contextualization, which will highlight the structures that drove the area into marginality, and contemporarily situate the state and city as mediators in the dispossession and isolation of stigmatized areas (Sampson and Wilson 1995; Wacquant, Slater, and Pereira 2014; Crump 2016). 
The social sciences and studies of the urban more generally have increasingly been engaging with elements of the feminist research epistemology, as a supplement to their

primary research methods, so that these issues can be addressed (Kwan 2002; Knigge and Cope 2016; Shelton, Poorthuis, and Zook 2015). The tenets of a feminist approach include reflecting upon power dynamics, empowering research subjects by giving them a voice, understanding the importance of difference and diversity, and situating knowledge within its specific context (McLafferty 2010). This study utilizes feminist research methodologies as an avenue to incorporate geographic imaginaries into an urban analysis, which leads us to the following section where the application of the geographic imaginary framework to an analysis of urban spatial segregation is discussed.

\section{APPLIED GEOGRAPHIC IMAGINARIES}

Urban areas are highly variegated landscapes with no single geographic imagination capable of capturing the level of diversity. Geographic imaginations, therefore, encompass widely recognized sections or districts of the city such as the central business district or the suburbs (Shelton, Poorthuis, and Zook 2015). The discourses that shape the geographic imagination of the district are often produced from an outsider's perspective and therefore does not fully appreciate the localized context (Wacquant 2006, 2008; Wacquant, Slater, and Pereira 2014). Examples of areas whose geographic imagination is defined from above include historically redlined neighborhoods and areas with disproportionately high poverty rates (Wacquant and Wilson 1989; Wacquant 2006; Wacquant, Slater, and Pereira 2014). The discourses surrounding these areas can turn stereotypical as the dominant source of information about these spaces comes from those outside such as politicians and the media. 
The geographic imaginary of their space becomes a negative exaggeration of their differences which discourages the public from experiencing the place themselves (Wacquant, Slater, and Pereira 2014). This strongly relates to the case study of Louisville's West End where nearly all mentions of it in the news and in conversation originate from the perspective of an outsider looking in (Shelton, Poorthuis, and Zook 2015).

The framework of geographic imaginaries is rooted in the investigation of local discourses as they exist within a specific social, political, and historical context. This framework can be used to expand upon the discourses of poorly represented places by engaging locals in the knowledge production process (Peake 2015; McLafferty 2010). Also, the stigmatized representations of these places can be situated within the broader power structures which shaped the discourse in the first place (Wacquant, Slater, and Pereira 2014; Crump 2016). An analysis of different urban issues can employ this framework in order to generate discourses of people's experiences with segregation, poverty, or housing and contextualize the results within the geographic imaginaries of their spaces as defined from the inside as well as the outside. In the next chapter, the methodologies used to analyze the geographic imaginations of Louisville's West End will be discussed in addition to the type of data collected and the final products of such an analysis. 


\section{CHAPTER 3: METHODS}

A critical analysis of geographic imaginaries of urban spatial segregation relies on the use of multiple methods targeting local discourses in order to eventually generate a narrative (Springer forthcoming). The selection of which methods to use becomes the foundation upon which the rest of the research is built, shaping how the research question is formulated, how the study area is approached, and what form the results will take (Philip 1998; Kwan 2002). Urban spatial segregation, as discussed in the previous chapter, has traditionally been approached through a city planning or public policy lens which engage quantitative methods (Baxter and Eyles 1999; Knigge and Cope 2016; Moss 1995; Philip 1998). Social research conducted with strictly quantitative methods is often critiqued by feminist and critical researchers for being positivist, reducing the diversity of communities into a few enumerated features, and incapable of providing adequate contextualizing to results (Moss 1995; Rose 1997; Silvey and Rankin 2010; Philip 1998; Katz 1994).

This study was designed to utilize a mixed-methodological approach, combining qualitative interview data with quantitative data sources, in order to generate a holistic narrative of Louisville residents' experiences with spatial segregation. The first section outlines the qualitative methods used to collect, organize, and analyze interview archives. The second section describes the synthesis of quantitative data, analysis of qualitative data, and visualization of these results in order to meld the content with the context (Knigge and Cope 2016). 


\section{METHODOLOGY}

Analytical tools such as content analysis software and geographic information systems (GIS) can be used together in an integrated methodological approach as a means of critically engaging complex relationships across space and time (Kwan 2002, 2004; Kwan and Ding 2005; Maclean \& Cullen 2009; Philip 1998). The combination of content analysis and GIS is well suited for studies of urban segregation because content analysis incorporates qualitative data while GIS provides a mode of spatializing qualitatively derived data which encourages an iterative and multidimensional examination of the data (McLafferty 2010). The remainder of this section will be spent defining these two analytical approaches which will lead into a discussion of how they will be used together within the context of this research.

Content analysis, the first analytical approach discussed here, is a systematic examination of communication in order to identify patterns, to isolate significant attributes, and to develop categories which help in the synthetization of the collection (Rose 2008). Communication in this sense includes the message, the meaning, and the discourse surrounding these exchanges either written or verbally (Rose 2008). Discourse, defined as the general way a group of people think and talk about things, is a dynamic way of thinking about communication which is why it is commonly incorporated into content analyses. Data used in this type of analysis can be in the form of interviews, survey responses, observations, photographs, and any other type of non-numerical data that is typically difficult to index (Rose 2008). There are two components to these types of data: manifest content, what is actually said, and latent content, the implied meaning (Berg 2008; Bengtsson 2016). With the data collected, it must all be compiled into a database and can be indexed by either the 
manifest or the latent content or a combination of the two. Typically, a content analysis is based on the manifest message, which can be queried within the database, and a discourse analysis focuses on the latent messaging.

These analyses are quite complementary and are used in tandem within the context of this study (Rose 2008). This analysis may be referred to throughout as either a content or a discourse analysis depending on the type of data that is referenced; however, the overall analysis is a single, iterative examination of the two data components (Bengtsson 2016). The goal of a content analysis is to organize data, whether it be qualitative or quantitative, according to a categorization scheme so that meaning can be drawn from the sources (Berg 2008; Bengtsson 2016; Rose 2008). For example, a content analysis of local coverage of a state fair could have a coding scheme with classes such as economic impact of hosting the event, local awareness and involvement, and negative local impacts (such as changes in traffic patterns or overcrowding).

The second analytical tool discussed in relation to bridging the gap between qualitative and quantitative research is qualitative GIS. There are two significant components to this tool: of grounding theory and of visualizing results (Knigge and Cope 2016; Kwan 2002). A study is grounded when it captures peoples' everyday experiences and uses this grounding to socially contextualize the data used throughout the analysis (Knigge and Cope 2016). Grounded theory can add dimensionality to the results through its use of multiple data sources and types by providing multiple points of view to be considered together (Kwan 2002, 2006; Kwan and Ding 2008; Kelly 2016; Walker and Hanchette 2015).

The second component, visualizing results, can be accomplished with GIS by spatially situating the data and, when paired with social grounding, enables an iterative 
exploration of the data between the spatial and the social which allows new themes to be identified, new questions to be raised, and new theories to be developed through critical reflection (Harvey and Kwan; Knigge and Cope 2016). An example of a study utilizing a grounded visualization approach would be the health geography case study on Long Island, New York where a group of women noticed that their community was experiencing very high rates of breast cancer, which they believed could be related to local environmental conditions, and in order to prove this they used GIS to pinpoint instances of breast cancer in their community and compared it against other areas across the state (McLafferty 2010).

Qualitative GIS is typically engaged in social research from one of two approaches: participatory translation and triangulation (Kwan 2008). The first begins with the collection of data through participatory qualitative methods such as interviews or focus groups, translates the results into a format compatible with GIS, and situates the final visual product within the context of study (Kelly 2016; Kwan 2002, 2008). One such study showcasing these techniques is Meghan Kelly's work remapping borders as experiential landscapes based on interviews with Syrian refugees and humanitarian workers (Kelly 2016). The analytical process here involved organizing a group of cartographers and symbolizing the Syrian border based on the selected interview passages in order to create an expanded "cartographic vocabulary" that is more reflective of personal experiences with the border (Kelly 2016).

The second approach to qualitative GIS, triangulation, relies on the integration of multiple data sources, recognizing that all data is partial, in order to piece together a mosaic of the socio-physical landscape (Kwan 2008; Knigge and Cope 2016). The goal of triangulation as applied to qualitative GIS is to generate theory grounded in narratives of lived experiences and compared against quantitatively derived data sets (Knigge and Cope 
2016). The process of triangulation is rooted in an acceptance of knowledge as partial, multiple, and situational (Moss 1995; Rose 1997). This means that knowledge, or data, is dependent on the context and time from which it is derived as well as the moment it is analyzed in the research process (Rose 1997). Feminist studies utilize triangulation in order to put the multiple partial knowledge in conversation with each other by iteratively and reflexively analyzing and reviewing the data (Rose 1997; Moss 1995). One study utilizing a triangulation approach to qualitative GIS is Knigge's work with community gardens in the Lower West Side of Buffalo, New York (Knigge and Cope 2016). The process here began with data exploration, first a socio-economic contextualization of the study area followed by participant observation, which informed how an interview would be constructed and distributed. Critical reflection was exercised throughout each stage of the research, relating new observations with previous ones, and influenced the trajectory of the further data exploration.

\section{DATA \& METHODS}

The first stage, quantitative contextualization, builds upon the historical discussion of the West End from Chapter 2 by empirically justifying the selection of the area as a socioeconomically distinct unit of analysis (Kwan 2012b; Knigge and Cope 2016). In addition to defining the study area based on local history and demographics, spatially explicit socioecological phenomena, such as environmental inequality and urban heat islands, are factors for further gauging the existence of boundaries on the cityscape (Knigge and Cope 2016). These factors are approximated by access to parks and green spaces and also the intensity of localized heat effects. Due to West End residents' disproportionate reliance on public 
transportation, an accessibility assessment of residents' ability to access parks and green spaces along bus routes will leverage information about how patterns of accessibility align with the spatial extent of the West End (Metro Housing Coalition 2010).

The main source of Louisville-specific, geographically referenced data used throughout this study was LOJIC, the Louisville/Jefferson County Information Consortium. Data collected from this resource included neighborhood boundaries, local bus routes, location of residential buildings, parks, tree canopy coverage, and urban heat indices. In order to maintain a critical approach while quantitatively contextualizing, the aim must be to show how different parts of the physical landscape are related to wider social issues without deterministic explanations or stereotypes being unrightfully reinforced (Harvey, Kwan, and Pavlovskaya 2005; Center for Neighborhoods).

The second stage, qualitative analysis, consisted of generating primary data and identifying archival sources to serve as the basis for the discourse and content analysis. Primary data was generated from the responses of a survey documenting residents' perceptions of Louisville and was distributed amongst the Housing Justice Work Group on Facebook as well as by well-connected colleagues on the same platform. This technique of connecting with participants is referred to as the snowball method of interviewing and does lead to some bias in the responses that are collected, but this method was decided on after many failed attempts to work with local community organizations whose mission statements aligned with my research goals. Approval from the Human Subjects Protection Program Office at the University of Louisville (IRB \# 19.1119) which allowed these responses to be collected. 
The data set compiled from these responses will contribute to the production of a local narrative by providing a point of comparison to the archival and interview story data which will be described below. The survey was composed of four multipart questions in order to start the conversation broadly and narrow down to the specific. Questions were designed to bring out descriptive words from the participants as they describe their area and to facilitate discussion on perceptions of their neighborhoods, of inequality, and of accessibility. Questions on the survey included:

1. How would you describe where you live? For example, which neighborhood, district, or region of the city do you live in?

2. What are some assets of your neighborhood? What are some deficits? How do the assets compare to the deficits? Do you feel there are more assets than deficits? Or do the deficits outweigh the assets?

3. How would you describe different neighborhoods, districts, or regions of the city? Why do you describe them this way?

4. Are there parts of the city that are hard to access or that are inaccessible? Are there parts of the city where you feel uncomfortable? Are there places that you try to avoid? What makes you feel this way about these places?

In addition to this data, two archives were selected to add to the database of quotations and interviews used for this stage of analysis. The Oral History Center at the University of Louisville holds a vast collection of oral histories available through the library's website and organizes the interview by collections. The interviews in these collections were conducted by the University of Louisville's Libraries and the Anne Braden Institute for Social Justice Research and included three collections of interest: African American Community Interviews, Fair Housing in Louisville, and the Kentucky Alliance Against Racist \& Political Oppression (Oral History Center). A local community organization, West of Ninth, hosts a blog with interviews of people who live in West End neighborhoods and they discuss a variety of topics including personal stories and 
contemporary issues (West of Ninth Stories). Over 200 stories have been posted between August 2017 and February 2020 and 82 were selected to draw quotations from due to their high relevance to the study. These archives were determined to be the most effect way of gaining insight into the communities' points of view because of the rapport they had already established with the interviewer and their insider standing.

Each archive was thoroughly examined for mentions of things related to the objective of this research: applying geographic imaginaries into an urban context. Guided by this, interviews were selected from the archive if they talked about life in their area, how they saw their home, how outsiders talked about their home, local resources or places they liked, and what they thought should be done to their area. For example, interviews where residents commented on having inadequate access to healthy food options were selected while interviews discussing their hardships and overcoming them were, while captivating, not selected. The selected interviews were compiled into a database compatible for use with the qualitative data analysis software Cloud Atlas.ti. This software is available for free online and serves as a way of streamlining the process of identifying commonalities across sources so that a classification scheme can be developed and applied to a content and discourse analysis. The classification scheme consists of Sub-Categories which should be "exhaustive, exclusive, and enlightening" so that as much data is incorporated into the analysis as possible (Rose 2008). The next step was to group the Sub-Categories into broader Conceptual Categories, but the development of the classification scheme will be discussed in much more detail below in Chapter 4: Results.

The third stage of the research, qualitative visualization, required the results of previous methodological stages in order to identify patterns across them. These 
visualizations provide an opportunity to integrate different types of information from different sources into a single product. For example, the methodological approach from the environmental inequities analysis will be applied to the thematic results from the content analysis in order to create a GIS map showcasing the connection between different socioeconomic variables. Esri's StoryMap online application will use the results from the content analysis in order to create a visual representation of the geographic imaginations of the resulting discourses. Each of the visualization products will be accompanied by a detailed discussion of how the results from previous stages were compared and connected as well as the implications of having a visual final product.

This chapter has described the quantitative and qualitative data sources utilized in order to generate a representative narrative of the study area. The first stage, quantitative contextualization, utilized key sources of secondary data including Louisville / Jefferson County Information Consortium (LOJIC), the Kentucky State Data Center, and the US Census Bureau. The second stage, content and discourse analysis, examined the University of Louisville's Oral History Center and the West of Ninth Stories blog as archival databases while also generating a dataset of responses to a Perceptions of Louisville survey. The third stage, qualitative GIS, synthesized the products of the first two stages in order to produce a final visualization. The results of all three stages, including descriptions of the final coding schemes, are presented below in Chapter 4. 


\section{CHAPTER 4: RESULTS}

The mixed-methodological approach used for this study was justified above as being well suited to address the research's primary objective of translating geographic imaginaries into an urban context. This chapter is divided into four sections and covers the results of each method in relation to how it accomplishes this primary objective. The first section evaluates the findings of the quantitative justification for the selection of the West End as a distinct study area. The second section details the development of the categorization scheme used to analyze the various sources of qualitative data. The third section directly builds upon this to outline the themes resulting from this analysis. The chapter closes with section four which documents the final products developed to visualize the results of each stage.

\section{QUANTITATIVE DESCRIPTION}

The designation of West End neighborhoods as a potential study area was supported in Chapter 1 where the district was historically contextualized within Louisville Metro. The level of segregation, along the lines of socio-economic composition and environmental equity, is empirically demonstrated below (Kwan 2012b; Metropolitan Housing Coalition, 2010; Hinko 2012). A trend that emerges from this evaluation is a spatial concentration in the West End of what is federally defined as "protected classes." A protected class is a governmentally recognized group who face discrimination based on an aspect of their identity including race, color, religion, sex, disability, familial status, national origin, sexual 
orientation, or gender identity (Metropolitan Housing Coalition, 2010; Anne Braden Institute, 2013).

Higher levels of poverty have been found to correlate with concentrations of protected classes, although it is itself not a protected class. This is illustrated below in Table 4.1 which highlights both demographic and socio-economic attributes of the population within the different spatial units of neighborhoods and the county. The attributes listed in the table are: 1) Total population; 2) Percent of the population that is White; 3) Percent of the population that is Black; 4) Percent of the population living below the federal poverty line; 5) Percent of the population that is receiving SNAP ${ }^{2}$ benefits; 6) Percent of female headed households; 7) Median household income; 8) Percent of the population with a college degree; 9) Percent of the population that is unemployed; 10) Percent of housing units that are vacant; and 11) The number of violent crimes per 100,000 people.

Table 4.1: West End Neighborhood Profiles. Data from Kentucky Data Center.

\begin{tabular}{|c|c|c|c|c|c|c|c|c|c|c|c|}
\hline & $\begin{array}{c}\text { TOTAL } \\
\text { POP. }\end{array}$ & $\begin{array}{c}\% \\
\text { WHITE }\end{array}$ & $\begin{array}{c}\% \\
\text { BLACK }\end{array}$ & $\begin{array}{c}\% \\
\text { IN } \\
\text { POV. }\end{array}$ & SNAP & $\begin{array}{l}\% \text { FEM. } \\
\text { HEADED }\end{array}$ & $\begin{array}{l}\text { MEDIAN } \\
\text { INCOME }\end{array}$ & $\begin{array}{l}\text { COLLEGE } \\
\text { DEGREE }\end{array}$ & $\begin{array}{l}\text { UNEMP } \\
\text {-LOYED }\end{array}$ & $\begin{array}{l}\text { VACANT } \\
\text { UNITS }\end{array}$ & $\begin{array}{l}\text { CRIMES } \\
\text { / 100,000 }\end{array}$ \\
\hline $\begin{array}{l}\text { JEFFERSON } \\
\text { COUNTY }\end{array}$ & 755,809 & $70 \%$ & $20 \%$ & $16 \%$ & $15 \%$ & $15 \%$ & $\$ 48,695$ & $36 \%$ & $8 \%$ & $10 \%$ & 600 \\
\hline CALIFORNIA & 6,523 & $9 \%$ & $87 \%$ & $46 \%$ & $46 \%$ & $34 \%$ & $\$ 16,591$ & $13 \%$ & $20 \%$ & $26 \%$ & 3,495 \\
\hline CHICKASAW & 6,299 & $2 \%$ & $96 \%$ & $24 \%$ & $32 \%$ & $31 \%$ & $\$ 31,497$ & $20 \%$ & $16 \%$ & $17 \%$ & 1,905 \\
\hline $\begin{array}{l}\text { PARK } \\
\text { DUVALLE }\end{array}$ & 5,780 & $3 \%$ & $96 \%$ & $32 \%$ & $35 \%$ & $48 \%$ & $\$ 25,044$ & $19 \%$ & $16 \%$ & $18 \%$ & 1,349 \\
\hline $\begin{array}{l}\text { PARK HILL / } \\
\text { ALGONQUIN }\end{array}$ & 9,607 & $30 \%$ & $66 \%$ & $52 \%$ & $44 \%$ & $32 \%$ & $\$ 19,894$ & $9 \%$ & $19 \%$ & $21 \%$ & 1,572 \\
\hline PARKLAND & 2,737 & $4 \%$ & $87 \%$ & $40 \%$ & $38 \%$ & $38 \%$ & $\$ 22,615$ & $12 \%$ & $21 \%$ & $28 \%$ & 2,411 \\
\hline PORTLAND & 10,626 & $63 \%$ & $32 \%$ & $39 \%$ & $46 \%$ & $33 \%$ & $\$ 23,705$ & $10 \%$ & $21 \%$ & $26 \%$ & 2,155 \\
\hline RUSSELL & 10,531 & $6 \%$ & $89 \%$ & $52 \%$ & $57 \%$ & $47 \%$ & $\$ 17,264$ & $11 \%$ & $29 \%$ & $19 \%$ & 2,678 \\
\hline SHAWNEE & 12,452 & $13 \%$ & $85 \%$ & $28 \%$ & $34 \%$ & $32 \%$ & $\$ 29,157$ & $16 \%$ & $19 \%$ & $14 \%$ & 1,173 \\
\hline
\end{tabular}

\footnotetext{
2 The Supplemental Nutrition Assistance Program (SNAP) is the largest federal nutrition assistance program providing benefits to eligible low-income individuals and families. Source: www.benefits.gov/benefit/361
} 
This concentration of protected classes within the West End is an example of spatial segregation on the socio-physical landscape of Louisville. Spatially segregated spaces are also connected to disproportionately high levels of exposure to negative environmental characteristics such as air pollution, limited access to green spaces, and localized urban heating effects (Anne Braden Institute, 2013; NPR 2020; Sampson and Wilson 1995; Stone 2016). The phenomenon of localized heating, referred to in the literature urban heat islands, is reflective of the long history of segregation embedded in local and federal governments' racialized policies for housing and development where the voices of minorities were, for generations, underrepresented or absent from the political process (Anne Braden Institute, 2013; Sampson and Wilson 1995; Wacquant and Wilson 1989). This study will quantitatively evaluate environmental injustices as aligning, or not aligning, with other manifestations of urban spatial segregation by comparing the amount of green spaces and tree canopy coverage between the West End and the rest of Jefferson County (Anne Braden Institute, 2013; Stone 2016)

The first environmental measure was accessibility to outdoor resources, such as city and state parks, and the second measure is tree canopy coverage. Parks were selected as a destination because they are the most commonly used recreational green spaces in the West End (Anne Braden Institute, 2013). Tree canopy coverage was selected as the second measure because of the significant role tree play in the urban environment by reducing the intensity of localized urban heat and reducing the amount of particulate matter in the air, for example (Stone 2016). To begin the park accessibility analysis, residents of the Downtown and West End portions of the city were identified as relying on public transportation much more heavily than residents living outside of these areas (Anne Braden Institute, 2013). For 
this reason, accessibility to outdoor resources was measured in terms of access to the bus lines servicing these parks. By analyzing the local bus network, it became apparent that only those most centrally located parks were accessible within a reasonable amount of travel time. Based on this, a zone classifying parks as accessible was defined by the spatial extent of a half mile buffer drawn around the study area neighborhoods (Kwan 2012b, 2012a). The results of this analysis can be seen below in Table 4.2.

Table 4.2: Tabulated results of environmental analyses on accessibility to parks and tree canopy coverage

\begin{tabular}{|l|ccc|}
\hline & West End & Jefferson County & Not West End \\
\hline Total Population & 54,458 & 693,604 & 639,146 \\
Total Area (acres) & $7,958.0$ & $248,029.8$ & $240,071.0$ \\
Acres of Park & 902.9 & $26,195.6$ & $25,459.3$ \\
\% Park & $11.35 \%$ & $10.56 \%$ & $10.60 \%$ \\
Acres of Park / & 1.66 & 3.78 & 3.98 \\
100 people & 1,112 & 63,435 & 62,220 \\
Acres of Trees & $13.97 \%$ & $25.58 \%$ & $25.92 \%$ \\
\% Trees & 2.04 & 9.15 & 9.73 \\
Acres of Trees / & & & \\
100 people & & & \\
UHI & 0.026469 & 0.010736 & \\
\hline
\end{tabular}

A trend across these different analyses was that the West End exhibited markedly different demographic, socio-economic, and environmental results when compared to Jefferson County as a whole. The concentration of protected classes within the West End was then connected to a disproportionate reliance on public transportation which in turn hindered residents' access to local resources. Figure 4.1, below, illustrates this connection by first showing the rate of vehicle ownership across the county and the location of resources including parks and libraries. There is a distinct concentration of low vehicle ownership rates in the West End and Downtown parts of the city, as shown with the darkly shaded 
census tracts. This map demonstrates how the West End is underserved in terms of accessibility to public resources such as parks and libraries and in terms of quantity with less than half of the park acreage per capita and one fifth of the tree canopy coverage per capita than anywhere else in the county.

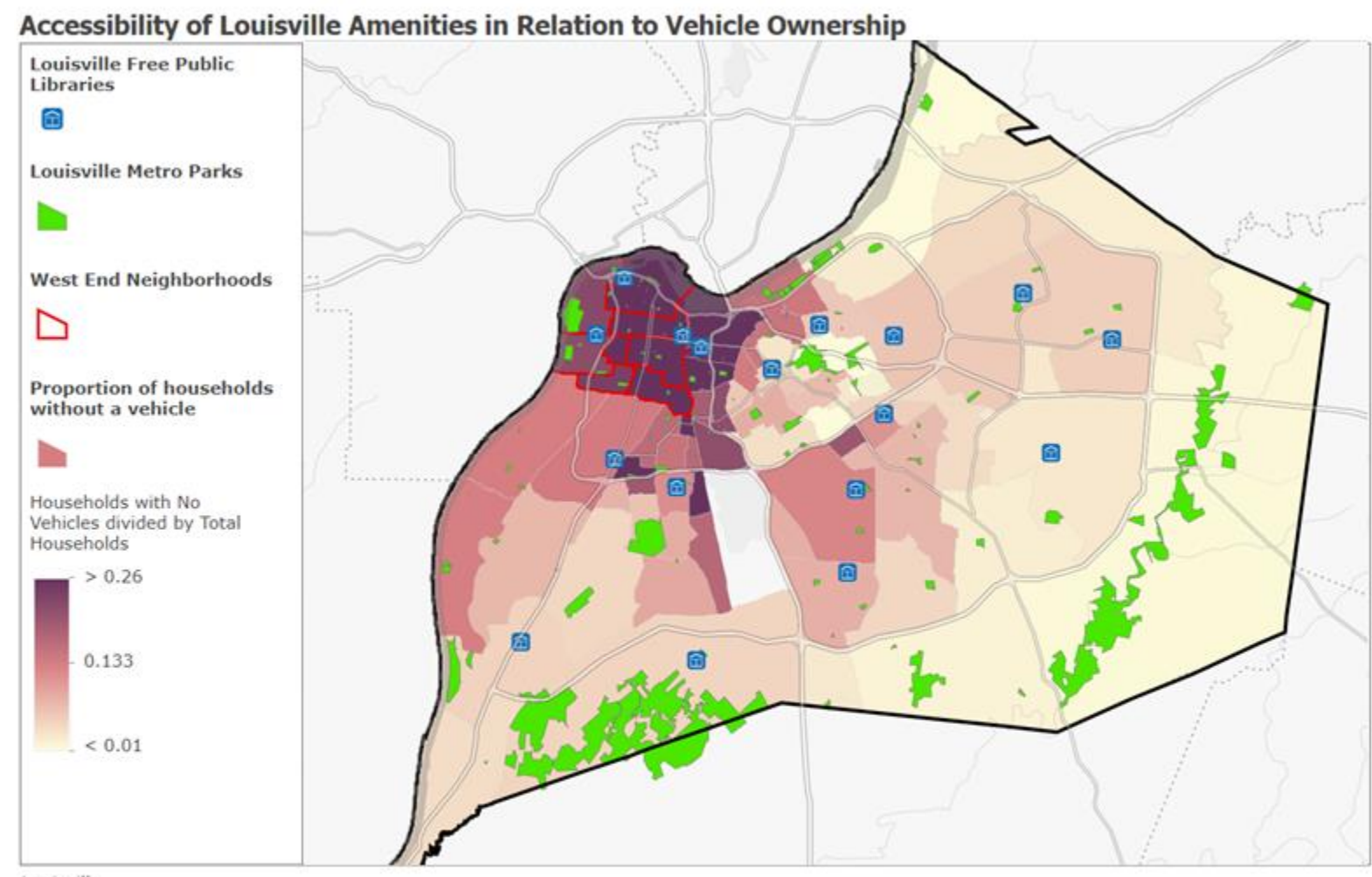

Louisville

Esri, HERE, Garmin, SafeGraph, METI/NASA, USGS, EPA, NPS, USDA | Esri, HERE, Garmin, SafeGraph, METI/NASA, USGS, EPA, NPS, USDA | The data was acquired and formatted through a contract with the Georgia Institute of Technology's Urban Climate Lab. | Esri, HERE, Garmin, SafeGraph, METI/NASA, USGS, EPA, NPS, USDA

Figure 4.1: ArcGIS Online Map of accessibility to Louisville amenities, specifically libraries and parks, in relation to vehicle ownership rates

\section{DATA CATEGORIZATION}

A total of 119 samples of qualitative data were part of the analysis, in the form of recorded interviews and survey responses, including 81 from the West of Ninth's Stories archive, 21 from the Oral History Center, and 17 online survey respondents totaling 100 question responses. Table 4.3 below provides a geographic breakdown of where the 
interview was conducted or where the online survey was completed. The interviews from the Oral History Center are not itemized in Table 4.3 because these interviewees did not have an easily identifiable point of origin since many were residents who had lived in multiple areas across the city.

Table 4.3: Itemization of interview sources

\begin{tabular}{|l|c|l|}
\hline \multicolumn{3}{|c|}{ West of Ninth Stories } \\
\hline Neighborhood & Count & Region \\
\hline California & 6 & West End \\
\hline Chickasaw & 9 & West End \\
\hline Park DuValle & 1 & West End \\
\hline Park Hill & 2 & West End \\
\hline Parkland & 13 & West End \\
\hline Portland & 6 & West End \\
\hline Russell & 32 & West End \\
\hline Shawnee & 12 & West End \\
\hline
\end{tabular}

\begin{tabular}{|l|l|c|}
\hline \multicolumn{3}{|c|}{ Survey Responders } \\
\hline Region & Neighborhood & Count \\
\hline Central & Old Louisville & 1 \\
\hline East End & Clifton / Crescent Hill & 3 \\
\hline East End & Smoketown & 1 \\
\hline East End & Highlands & 1 \\
\hline East End & Germantown / Schnitzelburg & 2 \\
\hline East End & Deer Park & 1 \\
\hline East End & Riverwood & 2 \\
\hline East End & St Matthews & 1 \\
\hline East & Norton Commons & 1 \\
\hline South East & Jeffersontown & 1 \\
\hline South End & Beechmont / Southside & 2 \\
\hline
\end{tabular}

In order to perform a content and discourse analysis, a coding scheme is required to more effectively organize and analyze the data. Word clouds, which are a visualization of word usage patterns, were generated as a first step towards creating a categorization scheme. The interviews selected from the two archival sources, the West of Ninth stories and the Oral History Center, were input into a world cloud generation website in order to gauge the prevalence of different words in comparison to my initial impressions of themes. These same interviews were also then input into the content analysis software Cloud Atlas.ti to streamline the organization process. This process was not linear but rather a cyclical process of reviewing the data, the code, and the literature: literature was required to guide the initial structure followed by data situating theories and reviewing the data or word clouds to 
validate theories, and then a return to the literature for theoretical support. The coding scheme consists of 'Sub-Categories,' based on the content and tone of interview samples, and 'Conceptual Categories,' determined by identifying commonalities between sub-categories (Bengtsson 2016). The final coding scheme, shown below in Table 4.4, consists of three conceptual categories, eight sub-categories, and was specifically designed to address both the manifest and the latent content across all of the collections.

Table 4.4: Classification scheme used for content and discourse analysis

\begin{tabular}{|c|c|c|c|c|}
\hline $\begin{array}{l}\text { Conceptual } \\
\text { Category }\end{array}$ & Definition & $\begin{array}{l}\text { Sub- } \\
\text { Category }\end{array}$ & Definition & Example \\
\hline \multirow{4}{*}{ Change } & \multirow{4}{*}{$\begin{array}{l}\text { Discussion } \\
\text { of how } \\
\text { things } \\
\text { either have } \\
\text { changed, } \\
\text { are } \\
\text { changing in } \\
\text { the present, } \\
\text { or things } \\
\text { they wish } \\
\text { would be } \\
\text { changed }\end{array}$} & Historical & $\begin{array}{l}\text { Remark on how } \\
\text { things were in the } \\
\text { past }\end{array}$ & $\begin{array}{l}\text { "Now, when I came up here in '89, the } \\
\text { residents were more neighborly." }\end{array}$ \\
\hline & & Needs & $\begin{array}{l}\text { Identification of } \\
\text { something the } \\
\text { community needs }\end{array}$ & $\begin{array}{l}\text { "They need YMCA down here. They } \\
\text { need a movie theater down here, too! } \\
\text { They need stuff for these kids to do." }\end{array}$ \\
\hline & & Optimistic & $\begin{array}{l}\text { Hopeful that this } \\
\text { change will occur }\end{array}$ & $\begin{array}{l}\text { "Link up, man. Stay together. We need } \\
\text { to get organized and stay together. Be } \\
\text { a unit, be one solid unit." }\end{array}$ \\
\hline & & Pessimistic & $\begin{array}{l}\text { Doubtful that this } \\
\text { change will occur }\end{array}$ & $\begin{array}{l}\text { "The streets are either gonna see you } \\
\text { dead, hurt, or in jail. It ain't no } \\
\text { resources for these kids." }\end{array}$ \\
\hline \multirow[t]{2}{*}{ Positive } & \multirow{2}{*}{$\begin{array}{l}\text { Explicitly } \\
\text { stated or } \\
\text { implied } \\
\text { positive } \\
\text { sentiment }\end{array}$} & Community & $\begin{array}{l}\text { Expression of the } \\
\text { values of } \\
\text { community }\end{array}$ & $\begin{array}{l}\text { "It gets a bad reputation due to some } \\
\text { of the acts that go on down here. As a } \\
\text { whole, the community is fabulous." }\end{array}$ \\
\hline & & Positive & $\begin{array}{l}\text { Positive aspect of } \\
\text { life in Louisville }\end{array}$ & $\begin{array}{l}\text { "I like the West End. It just makes me } \\
\text { feel like I'm home." }\end{array}$ \\
\hline \multirow{2}{*}{ Negative } & \multirow{2}{*}{$\begin{array}{l}\text { Explicitly } \\
\text { stated or } \\
\text { implied } \\
\text { negative } \\
\text { sentiment }\end{array}$} & Difference & $\begin{array}{l}\text { Expression of the } \\
\text { differences } \\
\text { existing between } \\
\text { groups of people }\end{array}$ & $\begin{array}{l}\text { "It's not even like how the news makes } \\
\text { it. They make the West seem like it's } \\
\text { Monsterville." }\end{array}$ \\
\hline & & Negative & $\begin{array}{l}\text { Negative aspect } \\
\text { of life in } \\
\text { Louisville }\end{array}$ & $\begin{array}{l}\text { "If you look at every corner, you see a } \\
\text { dollar store. If it's not a dollar store, } \\
\text { it's a pawn shop. If it's not a pawn } \\
\text { shop, you see a liquor store." }\end{array}$ \\
\hline
\end{tabular}




\section{RESULTING THEMES}

Classifying the data served as a jumping off point for a deeper examination of the interview sources in order to uncover the resulting themes discussed in this section. The first theme, territorial stigmatization, borrows its name from Wacquant's 2014 paper of the same name where he defined the term as a negative and noxious stereotype which comes to be the dominating definition of a place. This term was introduced earlier in Chapter 2 where the significance of historical contextualization was emphasized and the creation and perpetuation of discourse was connected to Bourdieu's power of representation (Wacquant 2014). Territorial stigmatization differs from previous practices of discursive "spatial smear" which Wacquant breaks down into five components: 1) The direct connection drawn between stigmatized places and poverty, degraded housing stock, and high levels of crime; 2) The universal reach of the act of territorially stigmatizing to nearly all cities where there exists a clearly defined "no-go zone;" 3) The classification of these spaces as a "counterworld" and completely separated; 4) The exaggeration of differences; and 5) The designation of these places as fraught with immorality (Wacquant 2014). Components 1, 2, and 4 are directly apparent throughout the sources compiled for this study and justifies the use of this more loaded term than one such as 'stereotype'.

The second theme, specific calls for change, is built upon the observed trend of residents very clearly identifying local problems and recognizing what is needed to overcome these problems. The problems discussed in these interviews were generally related to inadequate resources for children, insufficient access to grocery stores and healthy food options, not enough jobs or affordable housing, and high rates of violence. The third theme, sense of community, encapsulates both the positive and the negative references to different 
communities within the West End. It will also include residents' critiques of certain investment strategies undermining community values and hopes for what can be achieved if the community comes together. The remainder of this Resulting Themes section will delve deeper into these themes, draw upon exemplary quotations as support for the division of the interviews into these categories, and lay the foundation for developing the discourses that the geographic imaginaries will be applied to later in this chapter.

\section{Theme 1: Territorial Stigmatization}

"People out there don't know what's really going on inside. They tell people what they think but we don't feel that. They need the information from the people on the inside. I hate how the news will stress [stuff] and make it something that it really isn't." (Jay 2018, California resident)

This theme will be approached from three different perspectives: what the stigmatizing discourse contains, what the discourse originating from West End residents contains, and what the residents' reactions to these discourses are. The dominant discourse is built upon two fundamental sentiments - that the West End is crime ridden and dangerous, and that there is nothing drawing people west of $9^{\text {th }}$ Street (West of Ninth Stories; ; Cole 2018; Benjamin 2019; Brittany 2017; Benny \& Lucious 2017). Academic literature commonly argues that this discourse is generated from outside entities and from positions of power such as local government and the media. This argument of an outsider's discourse was supported by many separate interviews which commented on how the news outlets only do stories that cast the West End in a negative light and that the stories are highly exaggerated, often inaccurate, and don't show the whole picture (West of Ninth Stories). Two quotes in particular emphasize this point: 
"He was like, 'Man, folks with guns are in the West End! They'll kill you!' That stuff happens everywhere! The TV stations only announce the bad things about the West End because that's what sells. They don't announce anything that won't sell. When stuff happens, they get the message wrong. The news said that there was a shooting at Chickasaw Park. There was not a shooting at Chickasaw Park, it was in the Parkland area." (Lucious \& Benny 2017, Parkland resident)

"A lot of people have a misconception of what the West End is really about. It's not as violent and crazy as people seem to make it. It's actually a pretty close community. Sure, crime happens, just as anywhere else in the world." (Stella 2018, Russell resident)

Of the surveys collected from Louisville residents outside of the West End, $47 \%$ of the respondents said that they did not necessarily avoid the West End but that they did not have a reason to venture out there since they could not identify anything that would draw them west. Meanwhile, $35 \%$ of respondents admitted to avoiding the West End, $17 \%$ of whom said this was due to their primary source of information being the news and another $33 \%$ said they did not feel comfortable due to their unfamiliarity with the area. One respondent stated that they feel least comfortable in the southern and western areas of the city and acknowledged how "It is difficult to know whether this discomfort is also fear around those who are different from me in terms of culture and wealth." The connection between difference and discomfort is made across the literature of Orientalism, geographic imaginations, and racial segregation and is a vital component of the discourse perpetuating the territorial stigma of a place (Wacquant, Slater, and Pereira 2014).

The discourse originating from within the West End will be examined next and compared to the dominant-outsider discourse described above. Many residents discussed the area's high crime rates, the trouble with local kids joining gangs, the large amount of 
abandoned properties, inadequate access to amenities, and the continued decline of local businesses (Babinta 2019; Benjamin 2019; Shonda 2018; Shauna 2018). Some point to the increase in neighborhood violence as the most significant issue plaguing the area while some pinpoint the incident inciting their downturn as the 1968 riots in the Parkland area. This argument was made by older residents who experienced the transitional period after the riots and has also been made by local historical accounts of residential segregation (Wayne Barbour 2018; Damon 2018; Mr. Cole 2018; Alexander 1977) . The urban renewal projects of the 1970s are framed as direct recourse for the violence of the riots by targeting black businesses, particularly the thriving black business district along Walnut Street, and leading to permanent change in the impacted communities. One resident, who articulated the impact of these decisions on the contemporary landscape, said "we're just existing. They ain't really putting anything down here. I'm 60 years old now, and 28th Street have been the same since the riot [of '68]" (Wayne Barbour 2018, Park DuValle resident).

A key difference between the discourses generated by those inside the West End and those outside of the district is the scale at which things are framed. The outsider perspective approaches the West End as a singular unit, located adjacent to the rest of Louisville but situated within a different socio-economic context than the other parts of Louisville. The insider perspective recognizes the degree to which the experience of the West End differs amongst people and generalizes outside actors by framing them as one amalgamated entity. This can be interpreted in the universal use of they and them when describing outsiders acting upon the West End because the distinction between private and public investment projects does not matter; either way, the actor is seen as not having the community's best interest in mind. The following quote highlights this aspect of the insider's discourse: “they're tearing 
down our house over here. Instead of fixing them up, they're tearing them down... They're just taking homes away and nobody's going to stop and say anything about it. It just feels like nobody cares anymore" (Shawnee resident, 2018).

The final approach to territorial stigmatization is evaluating the response of residents to these discourses. The most prominent narratives from residents are about being misrepresented and about how the level of violence is greatly exaggerated and not reflective of their experiences. Throughout the interviews, there were many discussions on how the residents were disappointed in the way the news and media portrayed West End spaces and events. This sentiment is well illustrated in the following quotation: "I just stand up for the West End. I feel like we get talked about the most, down here, but we have the least. I don't see what they expect, when the resources aren’t here" (Parkland resident, 2017). Many residents also pointed to how they attempt to combat the stigmatization by trying to change how people talk about the West End and encouraging discussions focused on the positive local characteristics as opposed to the negative. Efforts such as these to change the way in which an area is conceptualized leads us into the next theme of West End residents identifying specific features in their communities they believe must be changed.

\section{Theme 2: Specific Calls for Change}

The problems in the community called out most frequently were street crimes, inadequate access to grocery stores and healthy food options, outside investment not being centered on community values, and a general lack of activities and resources for children. In addition to identifying local problems, there many residents who had a clear idea of what needed to happen in the community in order to resolve these problems. From the database of 
interviews compiled for this study, there were 100 specific calls for change identified which were sorted into 5 groups: 1) More community centers and activities for children; 2)

Investment strategies that benefit locals; 3) Unity within the community to combat violence; 4) More grocery stores and shopping opportunities; and 5) More publicly available resources. The groups will now be defined, contextualized within the West End, and framed in terms of the interviews examined for this study.

\section{More Community Centers \& Activities for Children}

"The West needs help, and more things for the kids to do. There's nothing for the kids, everything's gone. We need better community centers, that really gonna help the kids" (Russell resident).

"There's nothing in the neighborhood for kids to go to or do anything productive. They have to find something to do because they're bored, so they chose trouble" (Chickasaw resident, 2018).

Calls for more community centers and activities for children accounted for $31 \%$ of the needs identified by residents. This included calls for the opening and reopening of community centers as well as calls for more activities targeted towards children. Across the interviews, the problem of street crime and violence was overwhelmingly connected directly to children not having things to do. As of April 2020, there are 8 community centers, 2 Boys \& Girls Clubs, and 1 YMCA within the West End. While these centers offer many free activities, many of the sports programs cost money which families cannot always afford. Residents identified two things they believed were at the root of this connection: first, that kids were being left unsupervised outside of school hours, often because their parents worked more than one job, and second, that there was a general lack of role models in the community. These same residents pointed to coaches as being very significant role models 
in their own life, and as sports became less accessible, some kids came to view running the streets as an alternative. To be clear, this is not a generalization of the experiences of children without regular supervision or the experiences of people who turn to street violence: this is a theme that became apparent from the interviews of a limited number of residents who felt passionate about improving access to activities for children because they saw a connection between unsupervised children, street crime, and gang involvement.

Aside from community centers, whose activities do not always appeal to teenagers and young adults, there are extremely limited options for things to do that do not require travel out of the West End. There were many calls for the development of things for people of all ages to engage, including sit-down restaurants, movie theaters, skating rink, and paint ball facilities (Chickasaw resident, 2018; Parkland resident, 2017).

\section{Investment Strategies that Benefit Locals}

"I'm concerned about the lack of affordable housing and jobs. If people can't work, they can't live. There's no affordable housing here. The ones that are available, are getting bought by investors that don't live here nor care about the community. If you can't work and have a safe place to live, what kind of quality of life do you have?" (Chickasaw resident, 2018).

Calls for investments which would benefit locals accounted for $31 \%$ of the needs identified by residents. This included calls for more well-paying jobs, more affordable housing, and for local investments to be representative of residents' interests. The residents that discussed economic issues touched on topics such as homelessness, abandoned houses, insufficient supply of housing, and the need for more well-paying jobs within the West End. The topics of homelessness and abandoned houses were often addressed together because residents found it sickly ironic that there were so many homeless people while there were 
also so many empty houses. Some residents went further to argue that the abandoned houses could be transformed into homeless shelters or refuges as well as emergency housing for those getting back on their feet (Lance 2018; Richard 2018). Related to this were the discussions of affordable housing and how the lack of available housing stock in the West End was a point of concern for many residents, even those who are housing secure.

The literature on Louisville's economic inequities has documented the disproportionately far distance West End residents have to travel outside of their neighborhood in order to find a job paying a decent or livable wage despite the region having the lowest rates of car ownership in the city (Shelton, Poorthuis, and Zook 2015). These ideas are supported across the interviews as residents called for more local jobs that would also be capable of strengthening the local economy. Residents argued that the influence of outside private investors was twofold: first, that the investor's preference for the most profitable project was not always in line with the needs of the community, and second, that the investors' location outside of the community meant profits were not locally circulated and therefore not benefiting the local economy.

\section{Unity Within the Community to Combat Violence}

"Let's help each other and stop the violence. We're all in this together. Killing another person ain't gonna make it easier for you but make it harder. Help each other. Try to be a better world together, as a group" (Bruce 2018, Chickasaw resident).

Calls for unity amongst the community in order to combat local violence accounted for $25 \%$ of the needs identified by locals. This included calls for the community to come together and stop all of the hate as a means of reducing the occurrence of violent crimes. Despite a significant portion of the interviews containing some reference to disharmony or 
violence within the community, this figure is not higher because these references were often posed as a problem or a deficit to their community instead of an issue that could be resolved. The interviews showed that residents did believe that coming together was the key to overcoming many of the socio-economic problems afflicting their community. The discourse of "here in the West, we need to unite and respect one another" can in some ways be interpreted as reflecting residents' lack of trust in the city government to address their problems in a meaningful way (Joseph 2017). This discourse can also be interpreted as a way to employ unity and respect in order to reduce the hate which fuels local violence.

\section{Grocery Stores and Shopping}

"When we came down here, we had a Winn-Dixie, a drug store, and a bakery. We didn't have to travel. You just had to walk down an alley, turn a corner and you there. The grocery stores were on the corner. There was a hardware store was right down there. You didn't have to go far for nothing. Everything was in the community" (Sivonne 2017, Shawnee resident).

Calls for an improvement in the local shopping options accounted for $11 \%$ of the needs identified by residents. This included calls for more grocery stores, quality food options, and, overall, more locally owned and operated stores. The overwhelming presence of dollar stores across the West End was referenced in nearly every discussion on grocery and shopping availability, some going so far as to describe the commercial landscape as "a dollar store on every corner. If it's not a dollar store, it's a pawn shop. If it's not a pawn shop, you see a liquor store" (Joseph 2017). This theme of calling for changes to the quality and quantity of shopping centers was connected to concerns of the nutritional health amongst residents, of far-away stores being inaccessible to many residents, and of local economies suffering when corporations declare stores economically unviable (West of Ninth Stories). 
While many residents pointed to this as an issue that needs to be resolved, some went further to lay out what they saw as potential solutions, including increasing support of locally owned and operated stores, which would result in the greatest economic return to the area, and for improving the quality of already existing stores instead of starting from the ground up (West of Ninth Stories).

\section{Publicly Available Resources}

"Teach people about financial literacy in the community. That's stuff that they don't teach in school" (Pat, Alex, and Jay 2018, California resident).

Calls for more publicly available resources accounted for $4 \%$ of the needs identified by residents. This included calls for more educational programs, improved access to health resources, and assistance from local advocacy organizations. The services provided by the Louisville Urban League were described as vital assets to the community with residents discussing the need for more organizations like this. Additionally, inexpensive health resources were identified as lacking in the community which puts stress on residents who do not have means of transportation or of affording such care.

\section{Theme 3: Sense of Community}

The third and final theme identified across the West of Ninth and Oral History Library collections is the sense of community expressed by residents. When discussing their community and its members, residents had either a positive or a negative tone. The residents who had a negative tone often touched on topics such as a "lack of love," a lack of resources which would support community development, and reflections on how the community has degraded over time. One quotation captures these feelings of lacking love and community 
degradation: “It's way different from when I was little... They're just taking homes away and nobody's going to stop and say anything about it. It just feels like nobody cares anymore" (Renee 2018). These negative conceptualizations of community were often within the context of discussing local problems, such as those described in Theme 2, and how the lack of community resources was impacting the effectiveness of those trying to build the community up. One example of this was a football coach who stated that:

"Our challenges are that we don't have any bleachers. Sometimes parents will sit in their car because we don't have the seating. I go to other parks and they got bleachers. It will help us have more parents support. I go to another team's game and they have the best parent support. These kids need support. Some parents will just drop their kid off and leave. We need all parents to support because that's what keeps these kids going" (Coach Tone 2018, California resident).

Despite his efforts to organize activities to "keep them off the streets" and to act as a role model, he argues that the success of these programs is in part limited by the lack of parental and community support.

The residents who had a positive tone often touched on the closeness and supportiveness they witnessed amongst community members. These positive comments were usually part of a larger discussion where residents acknowledged and debunked the negative stereotypes associated with their area. By arguing that the stereotypes were exaggerations and not reflective of their experiences, residents were able to restructure the discourse so that the impact of the positive community components, such as "real and family ties" across the community, was emphasized. The positive descriptions of the West End community included "really friendly, genuine, and open," "friendly and chill," and overall, as feeling like home because of the closeness they felt to the people around them (Kaleigh 2017, 
Chickasaw resident; Jay 2018, California resident). In addition to closeness of the community, residents also highlighted the importance of supporting each other within the community. This was expressed in statements such as "the community sticks up for each other, even if they don't like each other," and "Every time a brotha man makes it to the top, we want to pull him down... Let them reach back and pull everyone up" (Lucious \& Benny 2017; Lyles 1977).

The three themes outlined here draw attention to some important components of the discourse originating from the West End. From the theme of territorial stigmatization, we can gauge how embedded the negative stereotyping is in the residents' conceptualization and internalization of western Louisville. From both the theme of territorial stigmatization and specific calls for change we can tell how frustrated people are with being inaccurately represented and with the impact of the stigmata on the local economy and community. The third theme, sense of community, ties all of these previous sentiments together, both the positive and the negative, to emphasize the power that remains in the hands of the community to reshape the discourse by encouraging people to take pride in where they live, to lift others instead of bringing them down, and to come together as neighbors. By analyzing the local discourse through the framework of geographic imaginaries, the influence of the local context was put in conversation with the perspectives of the residents which provided a more meaningful review of the discursive themes.

\section{QUALITATIVE VISUALIZATION}

Similar to content analysis, qualitative visualization is a technique of finding patterns and making connections across the data. This technique is able to build upon the results laid 
out in this chapter so far by incorporating the findings of different methodological stages and analyzing them together. This section will detail the different approaches to visualizing results beginning with GIS maps, used to compare different characteristics of Louisville, followed by the Esri StoryMap, the culminating representation of geographic imaginaries in Louisville, and closing with the many other products that went into developing the StoryMap.

The first set of findings visualized here relate to redlining in Louisville. This history of redlining was first introduced in Chapter 1 where it was suggested that racialized housing policies helped solidify segregation between residential districts. In Chapter 2, this claim was supported by literature discussing residential segregation across the United States and the specific ways that it manifested in Louisville. Figure 4.2 below is a georeferenced version of the 1936 redlining map with the modern neighborhood boundaries superimposed on top of it. Visually comparing the historic redlining boundaries with boundaries that are widely recognized and accepted today is a powerful way of reflecting upon the lasting impact of racialized residential segregation. This cartographic representation of boundaries allows the past to be put in conversation with the present by situating the modern designations within the historical context racially discriminatory perceptions of financial risk.

From this map we can see two primary concentrations of high-risk red zones adjacent to Downtown: one due west and the other east-southeast. The concentration to the east has undergone significant redevelopment and a demographic shift while the areas to the west and southeast remain predominantly African American and disproportionately impoverished. The one area within the West End that was not classified as red or yellow was on the western side of Shawnee where a white neighborhood was developed next to the largest urban parks 
on that side of the city, Shawnee Park and Fontaine Park. This settlement pattern, where areas near parks were designated white areas, relates to the discussion on environmental inequities from earlier in this chapter. In that section, protected classes were empirically shown to have less access to green spaces than residents in predominantly white areas, and here, this modern trend is contextualized within Louisville's long history of residential segregation.

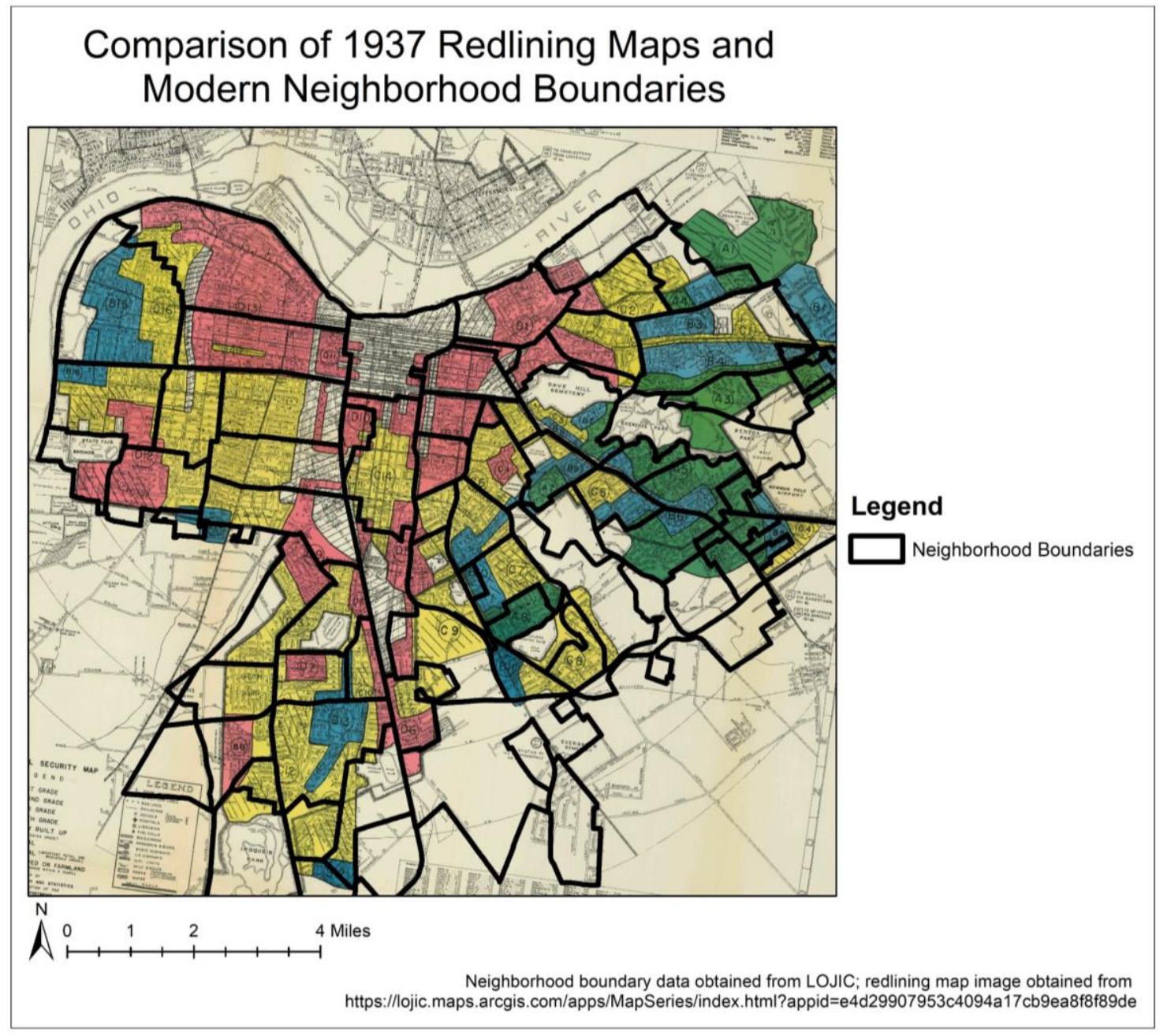

Figure 4.2: Georeferenced redlining map overlaid with modern neighborhood boundaries for visual comparison 
The next set of findings that will be evaluated here relates to accessibility. Earlier in this chapter, the accessibility of parks was mapped with respect to the rate of vehicle ownership. The methodology that was used to visualize these the connections between resources and means of transportation can be applied to the accessibility of other local resources such as day cares and health clinics. The call for more grocery stores and betterquality food options was common amongst the West End residents, so in order to gauge how inadequate the current grocery store situation is, this methodology was applied to grocery stores. The product of this is presented below in Figure 4.3 where the spatial relationship between vehicle ownership and the location of full-service grocery stores is demonstrated.

This map shows that there are significantly lower rates of vehicle ownership in the West End which suggests residents rely on public transportation. Despite the reduced mobility this grants West End residents, there are only three full-service grocery stores identified within this area. Based on the interviews of West End residents, the limited access to grocery stores means people are reliant on convenience stores and dollar stores as primary sources of food. This map serves as yet more evidence supporting residents' claims that the West End is underserved when it comes to accessing such vital resources. 


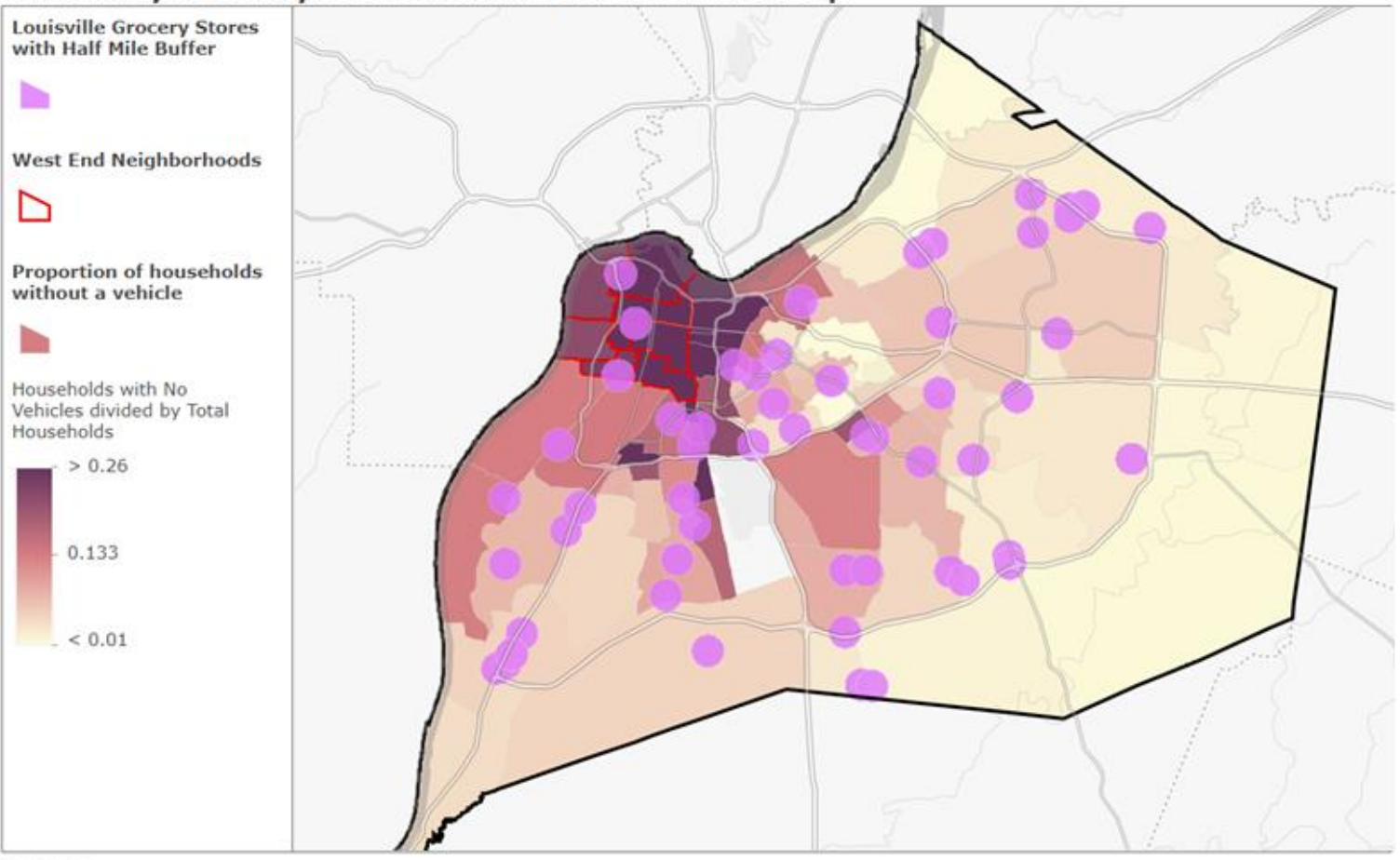

Louisville

Esri, HERE, Garmin, SafeGraph, METI/NASA, USGS, EPA, NPS, USDA I Esri, HERE, Garmin, SafeGraph, METI/NASA, USGS, EPA, NPS, USDA I The data was acquired and formatted through a contract with the Georgia Institute of Technology's Urban Climate Lab. | Esri, HERE, Garmin, SafeGraph, METI/NASA,

Figure 4.3: ArcGIS Online Map of accessibility to Louisville grocery stores in relation to vehicle ownership rates

The final set of results examined here relates to the discourses developed. The content and discourse analyses provided a means of identifying the perspectives of differentially-situated residents and putting them in conversation with each other. The positionality of the residents was relatively similar within the West of Ninth story archive and within the series of survey responses. The archive of oral histories, however, had a much more diverse pool of people interviewed and therefore exhibited the greatest variety of perspectives within a single collection. In order to encapsulate this array of perspectives, they will be aligned with either the discourse originating from West End residents or with the 
dominant discourse. Once this is determined, the discourses will be translated into a visual representation approximating the geographic imagination for each discourse.

The first set of perspectives examined comes from the archive of oral histories. This archive had the most prevalent differences in perspective compared to the other two sources. The primary reason for this is was the level of diversity in the participants' backgrounds as a resident, an advocate, or a city employee. The positionality of the Louisville Metro Zoning employees was very different from that of the fair housing advocates because they had diametrically opposing interpretations of local residential patterns. The Metro employees did not situate their work within the historical context of racialized housing policies but rather located their work as outside of a socio-political context. From this perspective, the zoning classification code R-4 was nothing more than a standard "filler" zone code for single-family homes dating back to the mass suburbanization of the post-World War 2 era (Bills and Hill 2012; Metropolitan Housing Coalition, 2010). Fair housing advocates situate the modern development codes within the racialized history. Their perspective allows them to frame the minimum square-footage requirement of R-4, which disproportionately segregates protected classes who rely on multi-family housing, and the system in place for developers to file for rezoning impedes the development of fair and affordable housing initiatives (Reid 2013; Howard 2012; Anne Braden Institute, 2013; Metropolitan Housing Coalition, 2010).

The next set of perspectives examined comes from the collection of survey responses. Within this collection, respondents framed the West End's economic status and poor reputation as caused by larger structural issues. The perspective of neoliberalism responsibilizes the individual for their economic standing, thus blaming low income people for being poor, but this is counter to what was observed in the survey responses where West 
End residents were not viewed as the cause of impoverishment nor were they viewed as inferior for not being able to overcome this standing. The respondents described their own neighborhoods as isolated and lacking diversity which I argue is related to their conceptualization of segregation existing at the neighborhood scale across the whole city. This perspective would frame the segregation experienced within the West End as not much different from that experienced in other parts of the city. By not historically contextualizing urban and residential segregation, this perspective falls short in describing and comparing things as they exist at the present time. Overall, the discourse of the survey respondents closely aligned with the dominant discourse in that they both originated from outside of the West End, do not rely heavily on individual experiences but rather on the discourse of others' experiences, and engage things as they presently exist without a historical perspective.

The final set of perspectives comes from the West of Ninth story archive. The grounded discourse examined here is exactly what the framework of geographic imaginaries seeks to put in conversation with the dominant discourse. This is an important component of the framework of geographic imaginaries because the groups described in the dominant discourse are not involved in its dictation. The power that comes from contributing to the discourse stems from the conceptualization of power as representation. This dynamic illustrates how groups can become more disenfranchised by not being a part of the knowledge production process and how their exclusion is rooted in a deeper discriminatory context.

The perspectives constituting the different collections have now been grounded in one of two discourses and contextualized within the West End. Esri's StoryMap platform was selected as the way of presenting the components of the geographic imaginations of 
Louisville residents through the lens of the dominant discourse and the discourse originating in the West End. Figure 4.4 below showcases the different types of information from the discourse that went into the formulation of geographic imaginaries, including culturally significant areas, areas that are commonly mentioned throughout the discourse, and quotations from interviews which reflect the previously discussed themes. The StoryMaps can be viewed in full at https://arcg.is/1emvWj0.

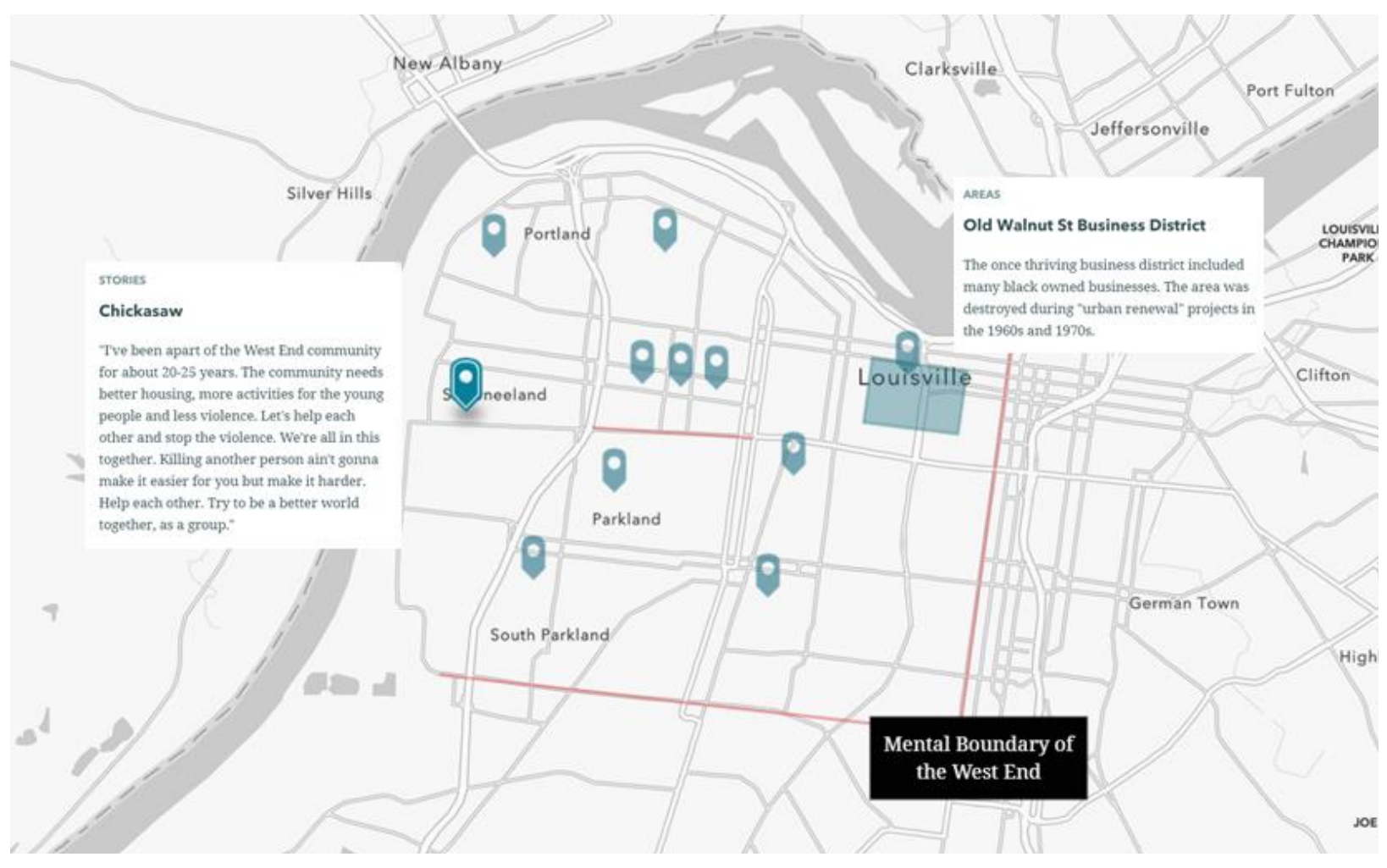

Figure 4.4: Screen capture of the online Esri StoryMap documenting some of the components of the geographic imaginations for the discourse originating from West End residents

The nature of this geographic imaginations approach is to delve deep into local discourse, however, representing the results in this manner runs the risk of generalizing the wide array of experiences and perspectives held by residents. The disempowering effects of overgeneralization were avoided here because the geographic imaginations are of the 
discourse, not the people, and the generalizations involved in articulating discourse have been widely acceptable in reviewing the way in which a group thinks and talks about things. There are some important components of one discourse that are not apparent in the other one. In the West End discourse, there were many references back to the old business districts in the area, such as those along Walnut St and Dumesnil St, and comments on how far those areas have fallen. Such a historical perspective was not engaged in the dominant discourse, rather, things were discussed in relation to each other based on how they presently exist on the landscape. This historical framing is important to the West End discourse because the annihilation of these once-thriving local economies is a tangible example of Louisville's racially discriminatory urban policies with impacts remaining on the landscape today.

The geographic imagination of Louisville's dominant discourse is presented below in Figure 4.5. One of the starkest differences between these discourses accentuated in these maps is the different way they employ scale. This was apparent in from interviews and survey responses because residents outside of the West End commonly used the beltloop highways I-264 and I-265 as a way of framing the city and a point of reference for locating places. The interviews from the West End engaged a much more localized scale that often did not extend to I-264 and the limited number of references made to the East End were usually no more specific than commercial hub, Bardstown Road. 


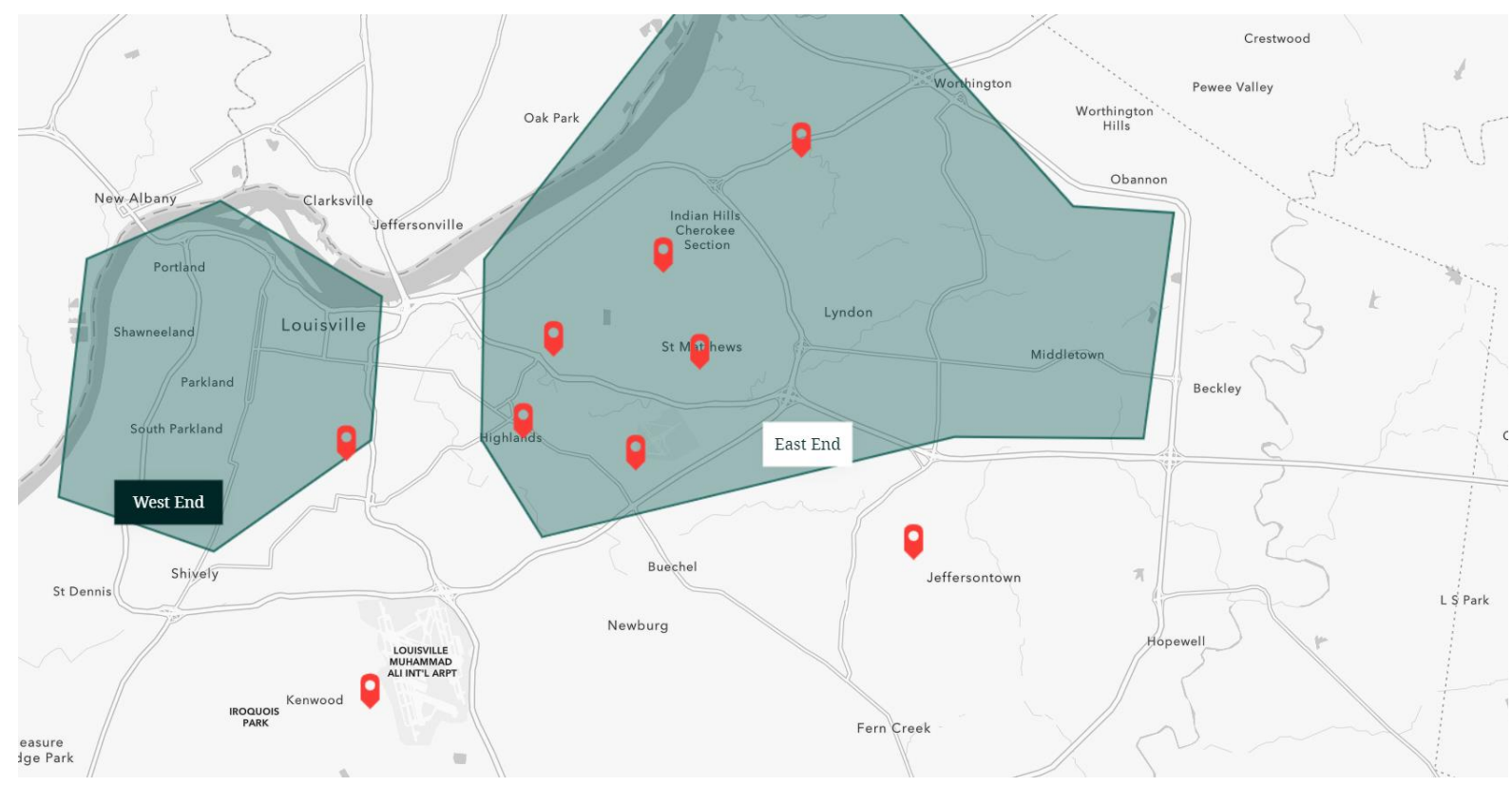

Figure 4.5: Screen capture of the online Esri StoryMap documenting some of the components of the geographic imaginations for the dominant discourse of Louisville residents

The two scales engaged with most are of the West End as a region and the much more local scale of a block or neighborhood. When the discussion was scaled up beyond the neighborhood, the residents rarely made more than two spatial designations: the West End and the rest of Louisville. This is a complex engagement of scale because the content of the interviews was on the street or neighborhood scale, but when the discussion shifted to Louisville as a whole, they would reframe themselves up to the scale of the West End. Through this conceptualization of space, residents discussed segregation as most severe at the scale of a district where the West End amalgamated all of the neighborhoods into the conversation of urban segregation. There could be a relation between this and a sense of community founded on the shared experience of hardships stemming from structural racism, and that uniting amongst themselves is the most promising route of achieving equality, however, any further conjecture of this is beyond the scope of this study. 


\section{CHAPTER 5: DISCUSSION OF RESULTS}

In Chapter 4, I presented the results of a quantitative contextualization, an accessibility analysis, a content and discourse analysis, and outlined the production of visual representations for each stage by engaging these results. This section will expand upon those results by connecting the findings from different methodological stages, comparing the narratives across the sources, and engaging them in order to discuss the geographic imaginations of urban spatial segregation. The section will begin by framing the socioeconomic, environmental, thematic, and visual results as dialectically related. This will build into a discussion of the different components constituting the geographic imaginaries of the discourses originating from the West End and those dominant across Louisville.

The first set of results, from the quantitative descriptions, included an evaluation of the West end as demographically and socio-economically distinct from the surrounding area and therefore a justifiable unit of analysis. These characteristics were then related to the concept of protected classes which was defined as group identities, including race, recognized by the government as being discriminated against. The demographic profiles highlight the degree to which the neighborhoods in the West End are racially segregated and the socio-economic characteristics accentuated the disproportionately high rate of poverty and economic inequality exhibited in the West End. Although poverty is not itself a protected class, it has widely been correlated with the designation of protected classes as a reflection of the structural discrimination faced by protected classes. Exposure to harmful 
environmental conditions, such as air pollution and urban heat effects, has similarly been connected to concentrations of protected classes. This angle was approached by completing an accessibility assessment approximated with proximity to parks and amount of tree canopy coverage. The results supported this connection between environmental inequities and concentration of protected classes within the West End.

The second set of results consisted of three thematic categories of the interview materials, including territorial stigmatization, calls for change, and sense of community. The first theme, territorial stigmatization, is connected to the quantitative descriptions outlined above because the narrative of a distinctly differentiated West End is supported by the socioeconomic and demographic evaluations performed. This empirical evidence reinforces the sense of division between spaces that was established through territorial stigmatization and in turn works to sustain the negative narrative surrounding the West End. Across the interviews with West End residents, the issue with this particular discourse was that it originated outside of their everyday lives; it did not engage the people living within these spaces and therefore did not produce a representative or reflective narrative.

The second theme, calls for change, included comments from residents regarding their dissatisfaction with the quality and upkeep of local resources such as parks and grocery stores. The results of the environmental inequities evaluation are related to this because the claim that protected classes in the West End are disproportionately subjected to environmental injustices is reflected in the local discourse of not having adequate outdoor recreational areas, being exposed to high levels of industrial pollution, and living amongst many abandoned buildings. 
The third theme, sense of community, is reflected across the West of Ninth stories where residents discussed the local issues, including those outlined above, alongside calls for the community to come together as a first step towards solutions. While the contents of this archive were divided amongst the three conceptual categories - positive, negative, and change - a review of the full-length interviews in the collection showed that the overall tone from the residents was positive and they exhibited a sense of optimism with regards to where their community was headed. Community members were shown to have a strong sense of what needs to happen to and within their community in order for the West End to succeed and prosper. Given how frequently this was expressed amongst the residents, why is this not a prominent component of the discourse surrounding the West End?

The power of shaping the discourse remains located outside of the West End and, as many residents pointed out, this leads to their point of view not being heard. Based on the findings laid out so far in this chapter, this could be attributed to the significant proportion of the population being designated as members of protected classes, but the very fact that this demographic concentration exists is due to Louisville's long history of systematic racial segregation. The pervasiveness of discourse-from-above was reflected in the responses to the survey I distributed online where the primary source of information on west Louisville was from the news, not from personal experience. The respondents all identified themselves as residing outside of the West End, as not having any personal connections to the area or to the people living there, and only $6 \%$ of them had any connections to the area through work. Respondents did not discuss the West End with any malice, but many did express having feelings of discomfort about going to some parts of the metro area given their unfamiliarity with the places. A lack of interaction between residents inside and outside of the West End is 
what sustains the territorially stigmatizing discourse and the conceptualization of these spaces as truly different. 


\section{CHAPTER 6: CONCLUSIONS}

Grounded in an analysis of the West End neighborhoods of Louisville, Kentucky, this study has used the framework of geographic imaginaries in order to document and illustrate the different conceptualizations of segregation exhibited across the discourses. To begin with, this framework of geographic imaginaries was defined as being rooted in the investigation of local discourses as they exist within a specific social, political, and historical context. It was defined as being structured around three key elements: contextualizing the subject of research, the research itself, and the researcher; composing a multidimensional geographic imaginary by engaging situated knowledges; and resulting in an empowering research model. Urban spatial segregation was identified as a suitable field of study to apply this framework given the dynamic power structures within the urban context and the concentration of many different groups within a limited spatial extent. An aspect of geographic imaginaries that was emphasized within the urban context was the way in which residents internalize physical and mental boundaries resulting from a history of racially discriminatory policies.

Segregation manifests on the urban environment in many ways, including divided consumer markets, concentrated poverty, unequally distributed green space, and reduced accessibility to vital resources such as grocery stores and adequate healthcare. In order to engage as many perspectives of segregation as possible, multiple methods using both quantitative and qualitative data were employed throughout this study. The methodologies 
used to analyze the geographic imaginations of Louisville's West End included contextualizing the district in relation to the surrounding area, assessing the levels of accessibility to environmental resources, performing content and discourse analyses of three collections of data, and visualizing results of different stages in order to most effectively identify patterns and connections. The first source, the Oral History Archive, provided a historical perspective as well as the perspectives of professionals in different fields of study. The second source, the West of Ninth Stories, provided the contemporary perspective and served as the basis generating the discourse of those within the West End. The final source, the responses to the online survey, provided a contemporary perspective from outside of the West End and was paired with the discourse of the media in order to outline the dominating discourse.

The results of this study included empirical support for the use of the West End as a case study and evidence that West End residents are underserved with regards to many different resources. From the content and discourse analyses, three themes of the discourse originating from the West End were identified. The first, territorial stigmatization, referred to the negative stereotypes engrained in the definition of the West End as well as the displeasure of residents not being accurately represented or talked about. The second theme, specific calls for change, highlighted the degree to which West End residents could identify what needed to be changed so that their community could overcome and thrive. The final theme, sense of community, included interview material commenting on the community as diffuse and unengaged, as welcoming and inclusive, and in need of more active participation and involvement. 
From all of this, the significant components of the two primary discourses, the dominant discourse and the one originating from within the West End, could be identified and discussed. The geographic imaginations of these two discourses were visualized through Esri's online StoryMap platform where two main differences we identified. The first was that the dominant discourse lacks a historical perspective while the discourse originating from the West End calls upon the local history throughout the interviews to highlight the impact of racially discriminatory local policy. The second was in the use of scale. Those engaging the dominant discourse generally talked about Louisville at a large scale and with greater specificity than those engaging the West End discourse. This other discourse was primarily on the very local scale, but when discussion was scaled up, there was much less specificity because the two spatial designations utilized were all of the West End neighborhoods grouped as one and then the rest of Louisville.

The difficulty of working with such diverse and complex discourses is determining whether or not the results are representative of truly existing local trends or if the results are only reflective of the compiled data. These two differences in the geographic imaginaries of the discourses could be attributed to the different approaches that were taken when the data was collected. The interviews collected by West of Ninth were done with the objective of empowering locals, providing them a platform to express themselves, and bringing the community together. The survey I designed was not meant to be leading, however the title of the survey was Perceptions of Louisville which could have directed them to think on a larger spatial scale when asked questions such as where they live. The impact that this would have on developing the geographic imaginations could be that the scale is unduly limited or broad. 
The objective of this thesis was achieved by applying a study of urban spatial segregation to the framework of geographic imaginaries in order to discuss different conceptualizations of segregation across Louisville. The framework of geographic imaginations was vital to this investigation of urban spatial segregation because power structures can be integrated into the conversation by contextualizing the discourse socially, politically, and historically, and by engaging underrepresented people in the knowledge production process. The distinction that was made between geographic imaginaries the framework and geographic imaginaries the discursive device is key to recognizing the utility of framing urban spatial segregation through the lens of geographic imaginaries. 


\section{REFERENCES}

Alexander, L. 1977. African American Community Interviews, ed. M. Brugman. University of Louisville: Oral History Center.

Allen, D., M. Lawhon, and J. Pierce. 2018. Placing race: On the resonance of place with black geographies. Progress in Human Geography 43 (6):1001-1019.

AnneBradenInstitute. 2013. Making Louisville Home For Us All: A 20 Year Action Plan for Fair Housing.

Babinta. 2019. Russell resident. In West of Ninth.

Barbour, W. 2018. Park DuValle resident. In West of Ninth.

Baxter, J., and J. Eyles. 1999. The utility of in-depth interviews for studying the meaning of environmental risk. Professional Geographer 51 (2):307-320.

Bengtsson, M. 2016. How to plan and perform a qualitative study using content analysis. NursingPlus Open 8 (14).

Benjamin. 2019. Parkland resident. In West of Ninth.

Benny, L. 2017. Parkland resident. In West of Ninth.

Bills, P., and M. Hill. 2012. Fair Housing in Louisville, ed. A. Duke. University of Louisville: Oral History Center.

Brittany. 2017. Park Hill resident. In West of Ninth.

Bruce. 2018. Chickasaw resident. In West of Ninth.

Cole, M. 2018. Parkland resident. In West of Ninth.

Crump, J. 2016. Deconcentration by Demolition: Public Housing, Poverty, and Urban Policy. Environment and Planning Development: Society and Space 20 (5):581-596.

Crutcher, D. 2013. A Tale of Two Cities. Louisville Magazine, March, 25-29.

Damon. 2018. Parkland resident. In West of Ninth.

Dawkins, C. 2006. The Spatial Pattern of Black-White Segregation in US Metropolitan Areas: An Exploratory Analysis. Urban Studies 43 (11):1943-1969.

Ebbs, H. 1977. African American Community Interviews, ed. M. Brugman. University of Louisville: Oral History Center.

Gieseking, J. J. 2017. Geographical Imagination. International Encyclopedia of Geography: People, the Earth, Environment, and Technology:1-8.

Goodwin, N. 1979. African American Community Interviews, ed. K. Chumbley. University of Louisville: Oral History Center.

Gould, M. 1999. Race and Theory: Culture, Poverty, and Adaptation to Discrimination in Wilson and Ogbu. Sociological Theory 17 (2):171-200.

Gregory, D. 1995. Imaginative Geographies. Progress in Human Geography 19 (4):447-485.

- 2004. The Colonial Present: Blackwell Publishing.

Hammond, J. 1979. African American Community Interviews, ed. M. Bobo. University of Louisville: Oral History Center. 
Hawthorne, C. 2019. Black matters are spatial matters: Black geographies for the twenty-first century. Geography Compass 13 (11).

Hinko, C. 2012. Fair Housing in Louisville, ed. A. Duke. University of Louisville: Oral History Center.

Hobich, F. 1977. African American Community Interviews, ed. M. Brugman. University of Louisville: Oral History Center.

Howard, L. 2012. Fair Housing in Louisville, ed. A. Duke. University of Louisville: Oral History Center.

Jay, S. 2018. California resident. In West of Ninth.

Jones, D. O. 1977. African American Community Interviews, ed. M. Brugman. University of Louisville: Oral History Center.

Joseph. 2017. Russell resident. In West of Ninth.

Kaleigh, A. 2017. Chickasaw resident. In West of Ninth.

Kent, A., and T. Frohlich. 2019. The 9 Most Segregated Cities in America. Huff Post 2015 [cited October 4 2019]. Available from https://www.huffpost.com/entry/the-9-mostsegregated-cities-in-america_n_55df53e9e4b0e7117ba92d7f.

Knigge, L., and M. Cope. 2016. Grounded Visualization: Integrating the Analysis of Qualitative and Quantitative Data through Grounded Theory and Visualization. Environment and Planning A: Economy and Space 38 (11):2021-2037.

Kobayashi, A. 2004. Geography, Spatiality, and Racialization: The Contribution of Edward Said The Arab World Geographer 7 (1):79-89.

Kwan, M.-P. 2002. Feminist Visualization: Re-envisioning GIS as a Method in Feminist Geographic Research. Annals of the Association of American Geographers 92 (4):645-661.

- 2012a. How GIS can help address the uncertain geographic context problem in social science research. Annals of GIS 18 (4):245-255.

- 2012b. The Uncertain Geographic Context Problem. Annals of the Association of American Geographers 102 (5):958-968.

Lance. 2018. Chickasaw resident. In West of Ninth.

Larson, S. M. 2017. Imagining social justice and the false promise of urban park design. Environment and Planning A: Economy and Space 50 (2):391-406.

Lipsitz, G. 2011. How racism takes place. Philadelphia, PA: Temple University Press. Lyles, L. 1977. African American Community Interviews, ed. C. Stieger. University of Louisville: Oral History Center.

Madsen, K. D., and D. B. Ruderman. 2016. Robert Frost's ambivalence: Borders and boundaries in poetic and political discourse. Political Geography 55:82-91.

Massey, D., and N. Denton. 1988. The Dimensions of Residential Segregation. Social Force 67 (2):281-315.

McKittrick, K. 2006. Demonic Grounds: Black Women and the Cartographies of Struggle. Minneapolis, MN: University of Minnesota Press.

McKittrick, K., and C. Woods. 2007. Black geographies and the politics of place. Cambridge, MA: South End Press.

McLafferty, S. L. 2010. Mapping Women's Worlds: Knowledge, power and the bounds of GIS. Gender, Place \& Culture 9 (3):263-269. 
MetropolitanHousingCoalition. 2010. Analysis of Impediments to Fair Housing Choice in Louisville, KY.

Mitchell, T. 1989. The World as Exhibition. Comparative Studies in Society and History:217-236.

Moss, P. 1995. Embeddedness in Practice, Numbers in Context: The Politics of Knowing and Doing. Professional Geographer 47 (4):442-449.

NPR. 2020. Studies Find Redlining Linked To More Heat, Fewer Trees In Cities Nationwide. NPR.

Pat, Alex, and Jay. 2018. California resident. In West of Ninth.

Peake, L. 2015. The Twenty-First-Century Quest for Feminism and the Global Urban. International Journal of Urban and Regional Research 40 (1):219-227.

Philip, L. J. 1998. Combining quantitative and qualitative approaches to social research in human geography—an impossible mixture? Environment and Planning A 30:261276.

Reardon, S. F., and D. O’Sullivan. 2004. Measures of Spatial Segregation. In Sociological Methodology, 121-162.

Reid, M. 2013. Fair Housing in Louisville, ed. N. Cissell. University of Louisville: Oral History Center.

Renee. 2018. Shawnee resident. In West of Ninth.

Rey, S. J., L. Anselin, D. C. Folch, D. Arribas-Bel, M. L. Sastré Gutiérrez, and L. Interlante. 2010. Measuring Spatial Dynamics in Metropolitan Areas. Economic Development Quarterly 25 (1):54-64.

Richard. 2018. Portland resident. In West of Ninth.

Rose, G. 1997. Situating knowledges: positionality, reflexivities and other tactics. Progress in Human Geography 21 (3):305-320.

Rothstein, R. 2017. The Color of Law: A Forgotten History of How Our Government Segregated America. New York: Liveright Publishing Corporation.

Sadahiro, Y. 2019. Statistical analysis of spatial segregation of points. Computers, Environment and Urban Systems 76:123-138.

Said, E. 1979. Orientalism. New York: Vintage Book. 1994. Culture and Imperialism. New York: Vintage Books.

Sampson, R. J., and W. J. Wilson. 1995. Towards a Theory of Race, Crime, and Urban Informality. In Crime and Inequality, eds. J. Hagan and R. D. Peterson, 37-54.

Schein, R. H. 1997. The place of landscape: A conceptual framework for interpreting an American scene. Annals of the Association of American Geographers 87 (4):660-680.

Shauna. 2018. Russell resident. In West of Ninth.

Shein, R. H. 2003. Normative dimensions of landscape. In Everday America: Cultural Landscape Studies after J.B. Jackson, eds. C. Wilson and P. Groth, 199-218. Berkeley, CA: University of California Press.

Shelton, T. 2017. The urban geographical imagination in the age of Big Data. Big Data \& Society 4 (1):1-14.

Shelton, T., A. Poorthuis, and M. Zook. 2015. Social media and the city: Rethinking urban socio-spatial inequality using user-generated geographic information. Landscape and Urban Planning 142:198-211.

Shonda. 2018. Russell resident. In West of Ninth. 
Silvey, R., and K. Rankin. 2010. Development geography: Critical development studies and political geographic imaginaries. Progress in Human Geography 35 (5):696-704.

Sivonne. 2017. Parkland resident. In West of Ninth.

Springer, S. forthcoming. Check Your Antroprivilege! Situated Knowledge and Geographical Imagination as an Antidote to Environmental Speciesism, Anthroparchy, and Human Fragility. Vegan Geographies:1-20.

Stella. 2018. Russell resident. In West of Ninth.

Stone, B. 2016. Louisville Urban Heat Management Study: Office of Advanced Planning and Sustainability.

Sundstrom, R. 2003. Race and place: Social space in the production of human kinds. Philosophy \& Geography 6 (1):83-95.

Tone, C. 2018. California resident. In West of Ninth.

Wacquant, L. 2006. Ghetto, Banlieue, Favela, etc. Tools for Rethinking Urban Marginality. In Urban Outcasts.

- 2008. Ghettos and Anti-Ghettos: An Anatomy of the New Urban Poverty. Thesis Eleven 94 (1):113-118.

Wacquant, L., T. Slater, and V. B. Pereira. 2014. Territorial Stigmatization in Action. Environment and Planning A: Economy and Space 46 (6):1270-1280.

Wacquant, L., and W. J. Wilson. 1989. The Cost of Racial and Class Exclusion in the Inner City. Annals of the Association of American Geographers:8-25.

Walker, M. A., and C. Hanchette. 2015. Residents' experiences in the aftermath of a HOPE VI revitalization project: A three-pronged, grounded visualization approach. Applied Geography 57:71-79.

WestofNinth. 2019. Walt \& Marshae Smith.

Yao, J., D. W. S. Wong, N. Bailey, and J. Minton. 2018. Spatial Segregation Measures: A Methodological Review. Tijdschrift voor economische en sociale geografie 110 (3):235-250. 


\section{APPENDIX A:}

Word Clouds 


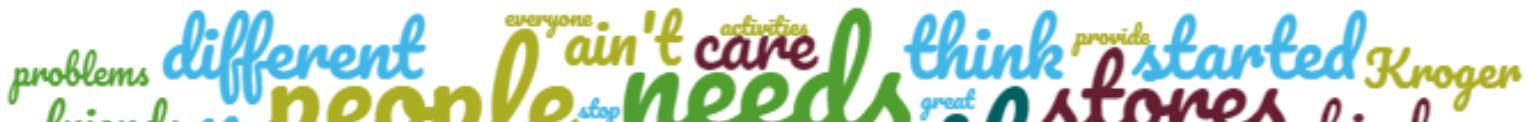
friends th peoplesther stores kind youth try connmwity bad another backstreets

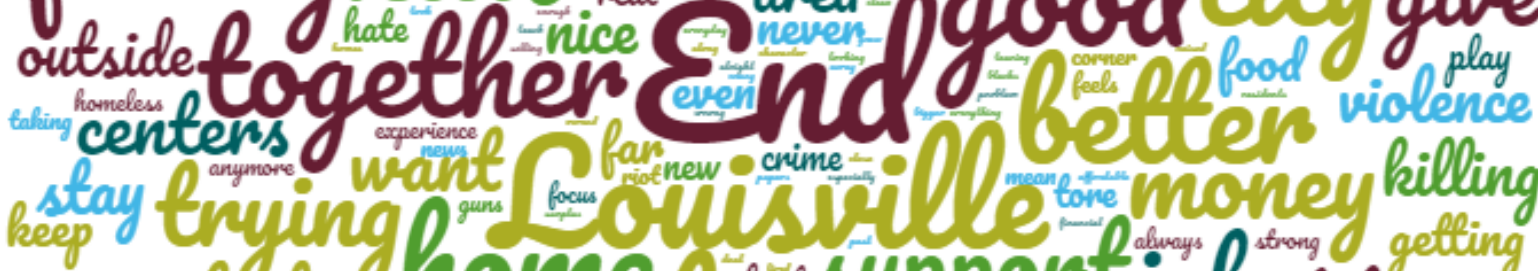
everybody home bus support jobs take everybody parents positive help slovene neighborhood

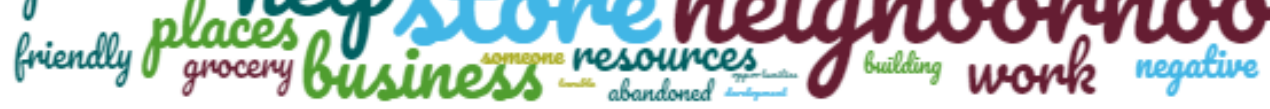

Figure A.2: Word Cloud generated with quotations from the West of Ninth Stories Created on wordclouds.com

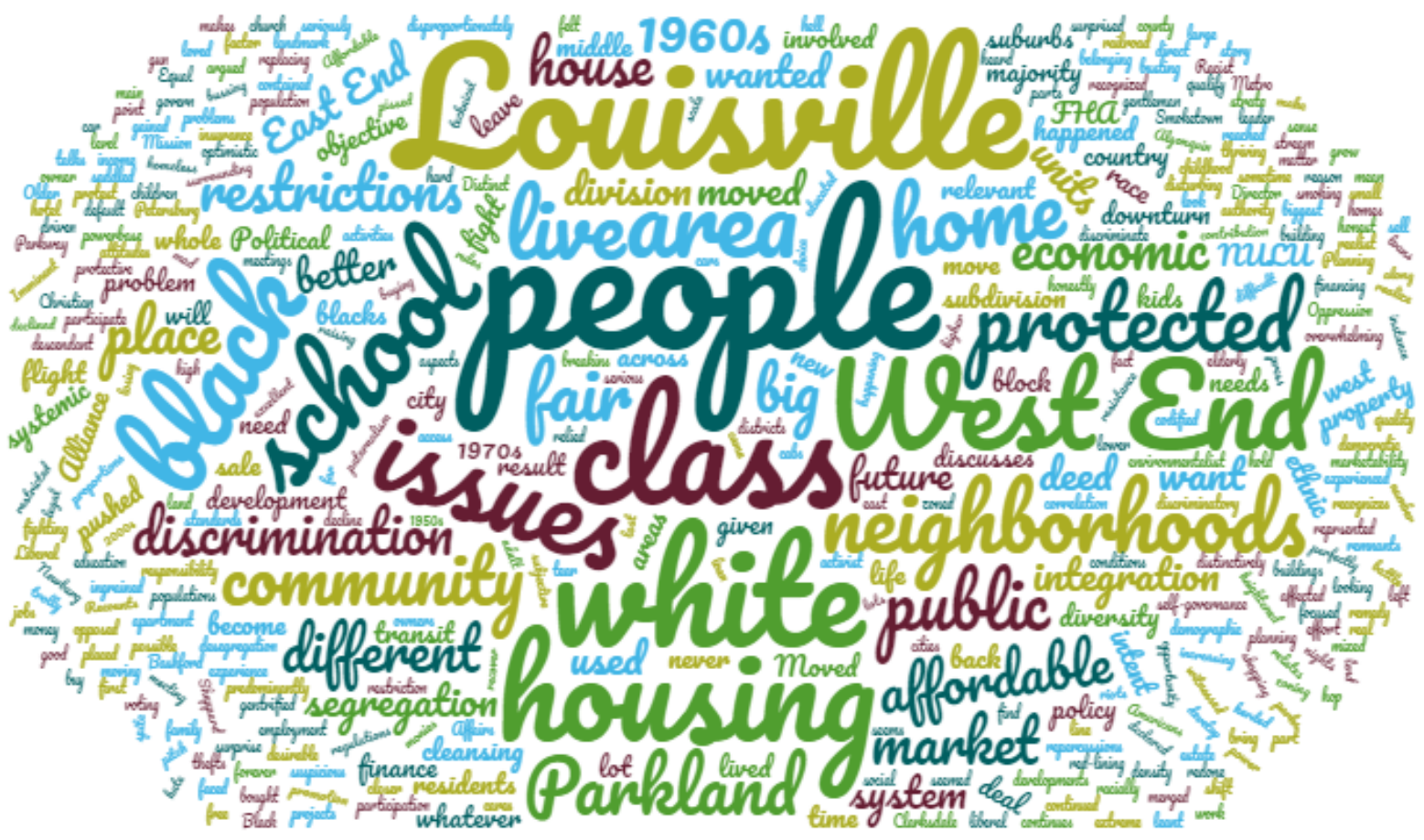

Figure A.1: Word Cloud generated with quotations from University of Louisville's Oral History Center Archive Created on wordclouds.com

76 


\section{CURRICULUM VITA}

NAME

CONTACT

EDUCATION

AWARDS

PRESENTATIONS

University of Kentucky Political Ecology Working Group

Urban Methodologies in Political Ecology: Empirically

Grounded Research Applications in Louisville and Beyond

$\begin{array}{ll}\text { MEMBERSHIPS } & \text { American Association of Geographers } \\ & \text { Ohio State University Alumni Association }\end{array}$
M.S. Applied Geography

University of Louisville

2018-2020

B.A. Geography

Ohio State University

2014-2018

B.A. History, research distinction

Ohio State University

2014-2018

Department of Geography \& Geosciences Graduate Teaching Assistantship Scholarship, UofL 2018-2020

Travel Grants from the Graduate Student Council and the

Undergraduate Library Research Fellowship, OSU 2017 Graduate Network in Arts \& Sciences, UofL 2020 